NISTIR 5672

\title{
Advanced Mass Calibration and Measurement Assurance Program for State Calibration Laboratories (2014 Ed)
}

Fraley, Ken L. Harris, Georgia L. 
NISTIR 5672

\title{
Advanced Mass Calibration and Measurement Assurance Program for State Calibration Laboratories (2014 Ed)
}

\author{
Fraley, Ken L. \\ Oklahoma Bureau of Standards, Retired
}

Harris, Georgia L. Office of Weights and Measures

This publication is available free of charge from: http://dx.doi.org/10.6028/NIST.IR.5672

September 2014

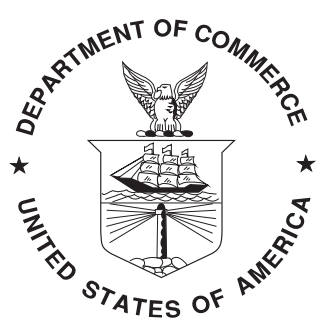

U.S. Department of Commerce Penny Pritzker, Secretary

National Institute of Standards and Technology Willie May, Acting Under Secretary of Commerce for Standards and Technology and Acting Director 


\section{Preface}

This publication was originally written by Ken Fraley, metrologist with the State of Oklahoma, and Georgia Harris, physical scientist with the NIST Office of Weights and Measures. Ideas from final users regarding publication content were sought at the 1994 National Conference on Weights and Measures meeting held in San Diego, CA. The publication was written to provide guidance for calibration laboratories in their desire to provide improved precision mass calibrations and for the NIST Office of Weights and Measures to ensure uniform evaluation of laboratories seeking to make mass measurements and be accredited at the advanced level of mass calibration.

Since the earlier editions $(1995,2005,2012)$ numerous practical questions have been raised and additional input has been sought from mass calibration experts. This edition seeks to enhance the original publications and provide additional guidance. Copies of Standard Operating Procedures 5 and 28 (3-1 Weighing Designs and Advanced Weighing Designs respectively) are included as an appendix. Additional weighing designs, equations for between-time standard deviations, and updates for uncertainty analysis are included as well.

\section{About the Authors}

Ken Fraley is a retired metrologist with the State of Oklahoma. He has over 20 years of experience in making precision mass measurements using weighing designs as described in this publication. He has carried out extensive experimentation and implemented measurement assurance programs to ensure that measurements made in the Oklahoma laboratory are consistent and uniform with those at the national level. As background experience, Ken developed the first draft of this document based on discussions with NIST and early users of weighing designs in the State laboratories, and provided a critical review of Advanced Laboratory Auditing Program (LAP) problems submitted after the first Advanced Mass Metrology seminar in 1993. He has also coordinated and analyzed several interlaboratory comparisons among laboratories working at the advanced level described in this publication. He has analyzed data, prepared preliminary and final analyses, and presented results of many interlaboratory comparisons conducted at basic, intermediate and advanced levels. In this edition, Ken has clarified ideas that now have over twenty years of refinement, has introduced extensive spreadsheet usage, and provided additional graphic content.

Georgia Harris is a Program Leader in the NIST Office of Weights and Measures. She provided direction and encouragement to Ken in developing the ideas and provided editorial support for the initial publication. In this revision, she has provided updated copies of SOP 5, SOP 28, ideas and content for spreadsheet analysis, and enhancements based on answering many technical questions from laboratories working at this level, and from reviewing numerous annual submissions for laboratories seeking formal Recognition at this level. The Office of Weights and Measures is responsible for providing technical support and guidance to the State legal metrology laboratories to ensure uniformity in the legal metrology measurement infrastructure; this publication is intended to provide support and guidance not only for State weights and measures laboratories, but also for other calibration laboratories seeking to implement advanced weighing designs. 
In the 1995 edition, the authors thanked the late M. Carroll Croarkin (NIST) for providing betweentime standard deviation formulae and assistance regarding updating mass calibration uncertainties to meet the ISO Guide to the Expression of Uncertainty in Measurement, to Jerry L. Everhart (JTI Systems, formerly with EG\&G Mound) for providing guidance in Process Measurement Assurance Programs, and to all of the metrologists who regularly participate in OWM training and regional meetings for their questions, comments, and desire to make precision mass measurements to the best of their capabilities. For the 2005 update, the authors thanked Hung-kung Liu of the NIST Statistical Engineering Division in supplying missing factors for the between-time standard deviation equations and for his critical review of the document. The 2012 edition was been updated to address updated definitions in metrological traceability. The 2014 update is primarily editorial with minor clarifications. SOP 5 and SOP 28 underwent additional updates to improve consistency in mass calibration uncertainties and reporting. 


\section{Contents}

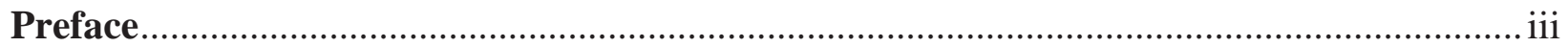

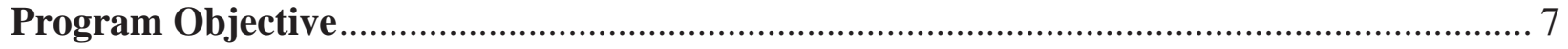

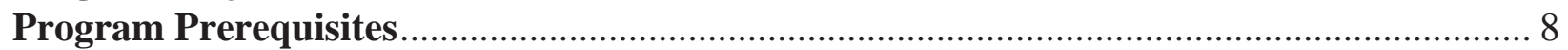

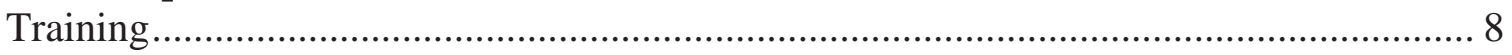

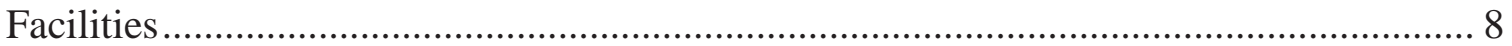

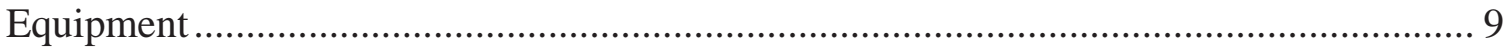

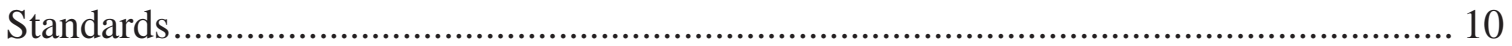

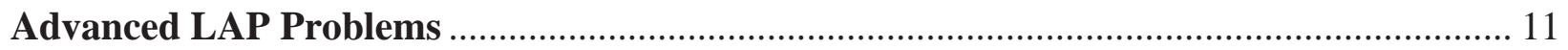

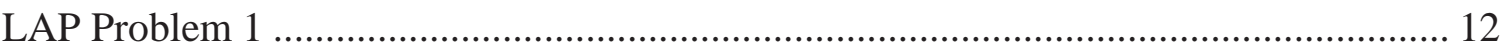

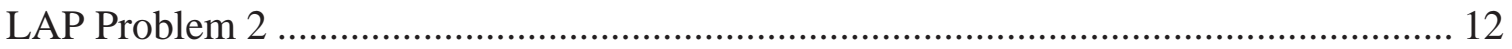

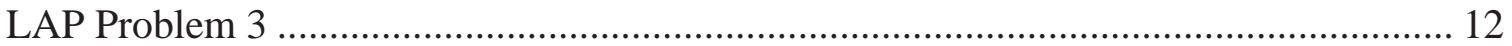

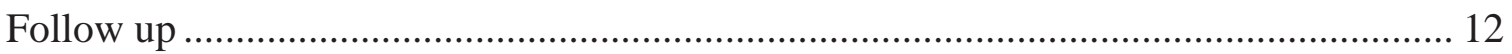

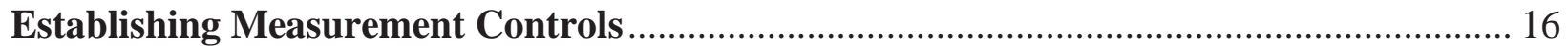

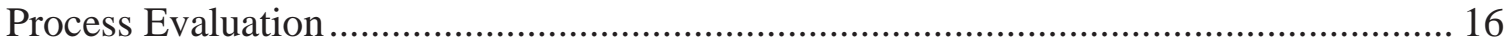

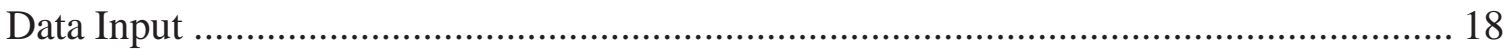

Handling the Output....................................................................................................... 19

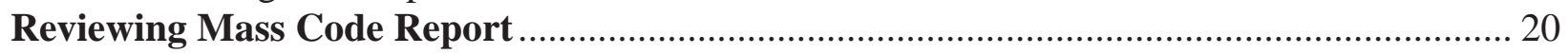

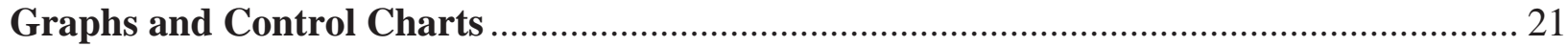

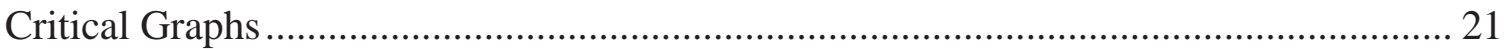

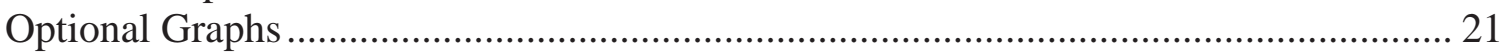

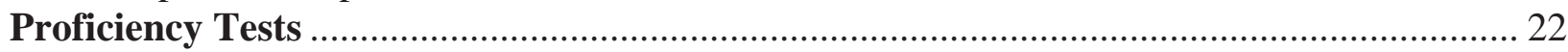

Evaluation Criteria for Proficiency Tests....................................................................... 22

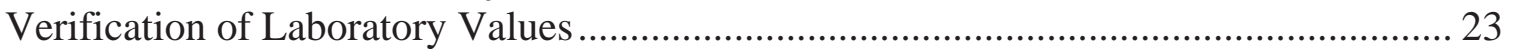

Verification of the Laboratory Precision ......................................................................... 23

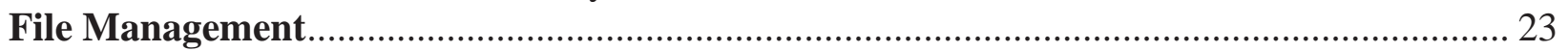

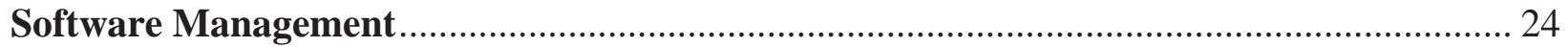

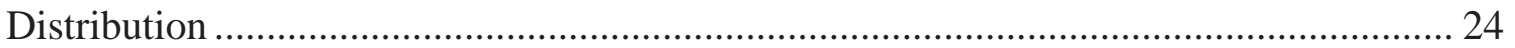

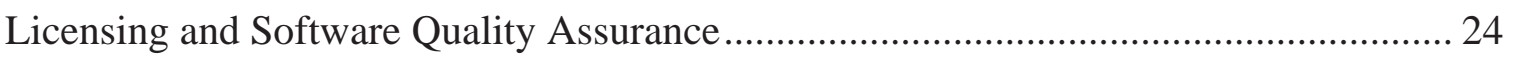

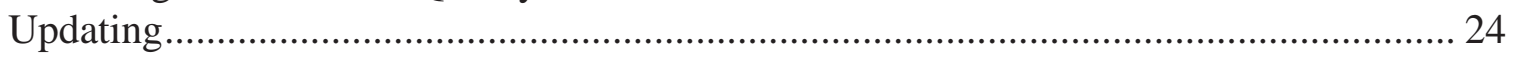

Approved Weighing Designs .......................................................................................... 24

Documentation of Standard Operating Procedures ................................................................. 25

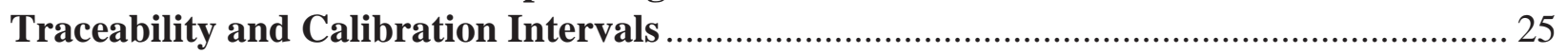

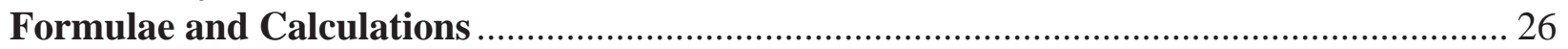


September 2014

Page vi 


\section{Advanced Mass Calibration and Measurement Assurance Program for State Calibration Laboratories}

\section{Program Objective}

This publication provides guidelines for evaluating data from advanced mass calibrations and for establishing measurement assurance programs in precision mass calibration laboratories. The NIST Office of Weights and Measures (OWM) will use these guidelines when evaluating advanced mass calibration data for State laboratories that request technical support, Recognition, and/or NVLAP accreditation.

Advanced mass calibrations use weighing designs, such as those found in NBS Handbook $145^{1}$ (SOP 4, 5), NISTIR 6969, Selected Publications ${ }^{2}$, NBS Technical Note $952^{3}$, and the NIST/SEMATECH e-Handbook of Statistical Methods ${ }^{4}$ that require the use of computer software (Mass Code) for the data reduction. These weighing designs are normally used when high precision (low uncertainty) mass measurement results are sought, although weighing designs can be used at any uncertainty level. The uncertainty reported using advanced weighing designs is based on the historically observed process of similar measurements and is very dependent upon correct procedures for defining these processes.

Reference calibrations (such as those provided by NIST) provide traceable measurement results for standards at one point in time and periodic calibrations are essential for ongoing assurance of metrological traceability. The major advantage in this Advanced Mass program is the ability to evaluate reference/working standards and the measurement process over time, providing ongoing assurance regarding accuracy and traceability of the mass standards for both the laboratory and its customers. Ongoing evaluation of the measurement process provides the laboratory with data that can be used to establish or adjust calibration intervals for reference standards, check standards, and working standards. The measurement assurance program is also critical for defining and reporting realistic uncertainties.

\footnotetext{
${ }^{1}$ Taylor, John K. And Henry V. Oppermann, NIST [NBS] Handbook 145, Handbook for the Quality Assurance of Metrological Measurements, November 1986.

${ }^{2}$ NISTIR 6969, Selected Laboratory and Measurement Practices, and Procedures, to Support Basic Mass Calibrations, 2014 Edition.

${ }^{3}$ Cameron, J. M., M. C. Croarkin, and R. C. Raybold, Technical Note 952, Designs for the Calibration of Standards of Mass, June 1977.

4 NIST/SEMATECH e-Handbook of Statistical Methods, http://www.itl.nist.gov/div898/handbook/, 2014.
} 


\section{Program Prerequisites}

The following items are listed as general guidelines for a laboratory conducting an internal evaluation of its program for suitability in the advanced mass calibration program for States. These guidelines have been established based on good measurement practices, good laboratory practices, and a similar fee-funded program (NIST Mass MAP) operated by the NIST Mass and Force Group. Many specific technical recommendations are taken from NIST Handbook 143, State Weights and Measures Laboratory Program Handbook, G. Harris, Editor, 2007, and NIST Handbook 150-2G: NVLAP Calibration Laboratories, Technical Guide for Mechanical Measurements, C. Douglas Faison and Carroll S. Brickenkamp, Editors, March 2004. Deviations from recommendations are occasionally made when data is available to support it; however, judgments should be made carefully when evaluating data, since some deviations from these practices will inadvertently increase measurement uncertainties and may contribute to measurement errors.

Training

$<\quad$ Satisfactory completion of a Fundamentals of Metrology course and the OWM Mass Metrology Seminar (or Basic Mass and Intermediate Metrology Training courses if completing seminars prior to 2012) and Laboratory Auditing Program (LAP) problems within the last five years are expected before attendance at the Advanced Mass Training course which is traditionally taught in odd-numbered years.

$<\quad$ Although required for NIST Recognition, attendance at the Regional Measurement Assurance Program (RMAP) meetings is not required to perform advanced mass calibrations. However, regular updates on precision mass procedures and issues are often provided at the regional meetings and proficiency tests are often coordinated through the RMAPs and will be required for Recognition or Accreditation.

$<\quad$ Satisfactory completion of the Advanced Mass Training course and Advanced LAP problems and successful application of these guidelines are expected before Recognition or accreditation at the Echelon I level as described in NIST Handbooks 143 and 150-2G. In addition to successful completion of proficiency tests. The problems ensure that suitable measurement assurance and uncertainty analysis data is in place in the laboratory to provide evidence of valid measurement results; the problems also provide additional demonstration of competency.

Facilities

$<\quad$ Environment - The temperature for the laboratory where mass measurements are made should be selected at a point between $18{ }^{\circ} \mathrm{C}$ and $23{ }^{\circ} \mathrm{C}$, with maximum changes of $\pm 0.3{ }^{\circ} \mathrm{C}$ per hour during a calibration series and a maximum change of $\pm 0.5{ }^{\circ} \mathrm{C}$ per 12 hours. Air flow must be low enough so that it does not interfere with balance or mass comparator operation. Humidity should be set between $40 \%$ and $60 \%$ relative humidity (e.g., $45 \% \pm$ $5 \%$ ). Environmental conditions must be monitored according to technical criteria and measurements should not be made when prescribed conditions are not maintained. Deviation 
from stated environmental parameters requires a thorough evaluation of the impact of the deviation on measurement errors and uncertainties.

$<\quad$ Vibration - The laboratory location and design should be such as to avoid or minimize potential sources of vibration that will interfere with precision mass calibration.

$<\quad$ Cleanliness - Good housekeeping practices and cleanliness specifications are found in NISTIR 6969, Handbook 143 and NIST/NVLAP Handbook 150-2G. Contamination from dust, hair, paper, shipping/packaging/storage materials like felt and velvet, and other air contaminants has been found to be a critical concern.

Equipment

$<\quad$ Computer and printer - A computer of sufficient memory and processing ability is essential. In the laboratory, every effort must be made to minimize the impact of introducing temperature gradients in the measuring areas. Laptops or other wireless or panel monitors are preferred to large heat-producing systems. The printer should be capable of routinely producing the 40-page reports generated by the Mass Code, and it should also be capable of printing graphics. The printer should not be located in a precision mass laboratory.

$<\quad$ Balances - Balances must be evaluated for suitable capacity, resolution, and repeatability and their ability to produce measurement results with standard deviations that meet the applicable uncertainty and tolerance requirements. A list of the laboratory's balances and process control chart data may be submitted to OWM for evaluation (required for State laboratories seeking Echelon I recognition). Control data for each balance should consist of the list of items shown in SOP 9 for measurement assurance in mass calibrations, with at least the following:

- $\quad$ Balance manufacturer, model number and serial number;

- $\quad$ Capacity and resolution;

- $\quad$ Balance configuration settings; and

- $\quad$ Pooled standard deviations (accepted within-process standard deviations, $s_{w}$, and accepted long term standard deviation of the check standard, $s_{t}$ ), showing number of degrees of freedom, loads, and specific weighing designs.

Laboratory balances will be evaluated to determine their suitability for this program. Minimum balance performance specifications recommended for this program are as follows: 
Table 1. Balance Performance.

\begin{tabular}{|r|r|}
\hline \multicolumn{1}{|c|}{ Loads } & *Standard Deviation should be less than: \\
\hline $20 \mathrm{~kg}$ & $1.5 \mathrm{mg}$ \\
\hline $10 \mathrm{~kg}$ & $0.20 \mathrm{mg}$ \\
\hline $1 \mathrm{~kg}$ & $0.050 \mathrm{mg}$ \\
\hline $600 / 500 / 400 / 200 \mathrm{~g}$ & $0.025 \mathrm{mg}$ \\
\hline $60 / 50 / 40 / 20 \mathrm{~g}$ & $0.0050 \mathrm{mg}$ \\
\hline $6 / 5 / 4 / 2 \mathrm{~g}$ & $0.0025 \mathrm{mg}$ \\
\hline $600 / 500 / 400 / 200 \mathrm{mg}$ & $0.0013 \mathrm{mg}$ \\
\hline $60 / 50 / 40 / 20 \mathrm{mg}$ & $0.00050 \mathrm{mg}$ \\
\hline $6 / 5 / 4 / 2 \mathrm{mg}$ & $0.00030 \mathrm{mg}$ \\
\hline
\end{tabular}

* The standard deviations in this table were developed by calculating 1/3 of OIML Class $\mathrm{E}_{1}$ tolerances, accounting for typical uncertainties associated with the standard and other factors, and developed by working backwards from a target expanded uncertainty. Many laboratories will not have balances or processes that can achieve these results on a routine basis.

$<\quad$ Barometer - A barometer having documented accuracy of $\pm 65 \mathrm{~Pa}(0.5 \mathrm{~mm} \mathrm{Hg})$ with evidence of metrological traceability (typically from an accredited laboratory) must be available.

$<\quad$ Thermometers - Thermometers to measure air temperature having accuracy of $\pm 0.1{ }^{\circ} \mathrm{C}$ with evidence of metrological traceability (typically from an accredited laboratory) are required. Temperature measurements made at this level are generally made within the balance chambers.

$<\quad$ Hygrometer - Percent relative humidity should be measured with an accuracy of $\pm 5 \%$ and have evidence of traceable measurement results (typically from an accredited laboratory).

$<\quad$ An environmental recording device is required for monitoring laboratory conditions. Even though a number of environmental corrections are made during the mass measurement process, ensuring environmental stability during the 24-hour period preceding a calibration (particularly for temperature) is important to ensure proper thermal and environmental equilibration of mass standards.

Standards

$<\quad$ Reference (formerly called Primary) Standards - A minimum of two $1 \mathrm{~kg}$ reference standards (four $1 \mathrm{~kg}$ reference standards are recommended) with calibration and density determination needed and metrological traceability to the International System of Units (SI) usually through a National Metrology Institute, such as the U.S. National Institute of Standards and Technology. Two reference standards should be calibrated at least every four years. The second set of two kilogram standards should then be calibrated two years after the reference standards. In this way, calibration values used in the laboratory will be less than two years old. Even though a measurement assurance program that monitors the reference 
kilogram standards will be in place to demonstrate ongoing stability and validity of the mass values, mass calibrations are performed through comparison methods and all standards may be changing or drifting and fail to identify systemic changes. If only two reference standards are available, and if they are used with equal frequency, the measurement assurance program will not be considered adequate without some type of verification using standards from outside the laboratory that have recent suitable calibrations. GMP 11, Good Measurement Practice for Assignment and Adjustment of Calibration Intervals for Laboratory Standards, and GMP 13, Good Measurement Practice for Ensuring Traceability (or other equivalent procedure), must be implemented in the laboratory to document metrological traceability and calibration intervals that the laboratory will follow. (See discussions on Proficiency Tests and Graphs and Control Charts.)

$<\quad$ Check standards - Check standards (sometimes called control standards) must have suitable calibrations with evidence of metrological traceability. Having the check standards calibrated by a National Metrology Institute or an Accredited laboratory provides an effective mechanism to identify and evaluate biases that may be occurring in the measurement processes that would otherwise go undetected; having an external calibration is essential for evaluating bias in addition to monitoring the output of the measurement process.

The check standards must be one-piece design (to provide the necessary stability and to act as surrogates to the reference standards) with known densities and have been assessed to comply with limits on magnetic susceptibility as required in ASTM and OIML standards, in the following decade denominations: $1 \mathrm{~kg}, 100 \mathrm{~g}, 10 \mathrm{~g}, 1 \mathrm{~g}, 100 \mathrm{mg}, 10 \mathrm{mg}, 1 \mathrm{mg}$. “ASTM Class 1, Type 1, Grade S” or “OIML Class $E_{2}$ ” verbiage may be used if specifying weights for purchase. Additional check standards above 1 kilogram are needed to handle the entire range of calibration services, e.g., $10 \mathrm{~kg}$.

Measurement Assurance (Control)

$<\quad$ The laboratory needs to have a measurement assurance (control) system already in place before trying to perform advanced mass calibrations. Practical, hands-on experience in the laboratory is essential to making good mass measurements. A current measurement assurance system and data are essential for initial statistical analysis, for demonstrating measurement proficiency, and/or justifying any deviations from these recommendations which also require documentation and validation.

\section{Advanced LAP Problems ${ }^{5}$}

See Figure 1 for a graphic view of the components required in a complete analysis of the Advanced LAP problems.

5 Laboratory Auditing Problems are assigned to each State metrologist upon completion of the Advanced Mass seminar. Successful completion of the LAP problems and applicable proficiency tests are required by State laboratories prior to receiving Recognition or Accreditation. 
Laboratory Auditing Program (LAP) problems are used for establishing a baseline for the initialization of the check standards, to provide initial data to assess the between-time component of the measurement process, for providing validation on uncertainty statements, and for evaluating the proficiency level at which the laboratory uses the Mass Code. The data collected in the LAP problems is reduced by each laboratory using the Mass Code. Each qualified metrologist must complete training and the Advanced LAP problems and be able to reduce and analyze their own data. Each laboratory is responsible for graphing and analyzing data when determining the "in control" or "out of control" condition of their standards (see sections on Establishing Measurement Control and Graphs and Control Charts). Observed surveillance values must be compared to the reported reference values to determine the level of control. A copy of all data, data files, reports, graphs, and final analysis for State laboratories are to be sent to OWM for evaluation along with the most recent reference calibration reports for the standards used. The final written analysis, demonstrating a thorough understanding of the measurement assurance system and uncertainty analysis at this level of work is considered the most critical component of completing the Advanced LAP problems.

NOTE: Standards should not be cleaned using solvents during the initial data-collection period as these tests will provide data for determining the total and between-time standard deviations for each series. Cleaning standards changes their mass values and may invalidate the calibration. Cleaning plans and procedures must be documented as a part of the laboratory procedures. At least 7 to 10 days are required for environmental equilibration on standards that have been cleaned with solvents prior to recalibration; however, several months are often required. New mass standards may require several years before suitable stability has been attained.

LAP Problem 1: $\quad$ Ten (10) complete runs on reference/working State standards from $1 \mathrm{~kg}$ to $1 \mathrm{mg}$. (Initial data from the first one or two runs may be submitted to be sure the laboratory is on the right track.)

\section{LAP Problem 2: $\quad$ Two (2) complete runs on standards from $30 \mathrm{~kg}$ to $2 \mathrm{~kg}$.}

The series selected when ascending from $1 \mathrm{~kg}$ may be the same as those used when descending; however, a single restraint is usually used and the between-time standard deviation formulae must be derived or obtained from the referenced design job-aid spreadsheet.

If the laboratory maintains both metric and avoirdupois standards with NIST traceability, one additional LAP problem should be conducted. The avoirdupois standards are calibrated through a crossover method at the $1 \mathrm{~kg}$ level against $2 \mathrm{lb}$ and a $2 \mathrm{lb}$ summation made of the reference $1 \mathrm{lb}$ standards. The $1 \mathrm{lb}$ values are assigned reference values through additional measurements and the entire avoirdupois system is calibrated with the $1 \mathrm{lb}$ standards as the starting restraint. Special tare weights (92.815 g) can be obtained to facilitate this process.

LAP Problem 3: $\quad$ Two (2) complete runs on standards from 50 lb to $1 \mu \mathrm{lb}$.

Follow up: $\quad$ Note measurement assurance guidelines and traceability for using the initial LAP problems in continuing measurement assurance. 
Note: Two complete runs is not adequate to provide data for establishing initial limits nor for establishing a baseline for acceptable measurement assurance nor for validating uncertainties at this level. If the laboratory plans to provide internal calibration results or extended service to customers, additional data must be obtained and analyzed. Process statistics determined with limited data must have uncertainties that reflect the actual degrees of freedom. The laboratory may limit their application of this process to the smaller mass levels (e.g., $1 \mathrm{~kg}$ to $1 \mathrm{mg}$, or $100 \mathrm{~g}$ to $1 \mathrm{mg}$ ). LAP problems 1 and 2 may be combined if a limited range will be used for this level in the laboratory. For example, ten runs from $10 \mathrm{~kg}$ to $1 \mathrm{mg}$ would be another acceptable approach. If the laboratory does not plan to use the Mass Code for avoirdupois standards, LAP problem 3 is not required. 


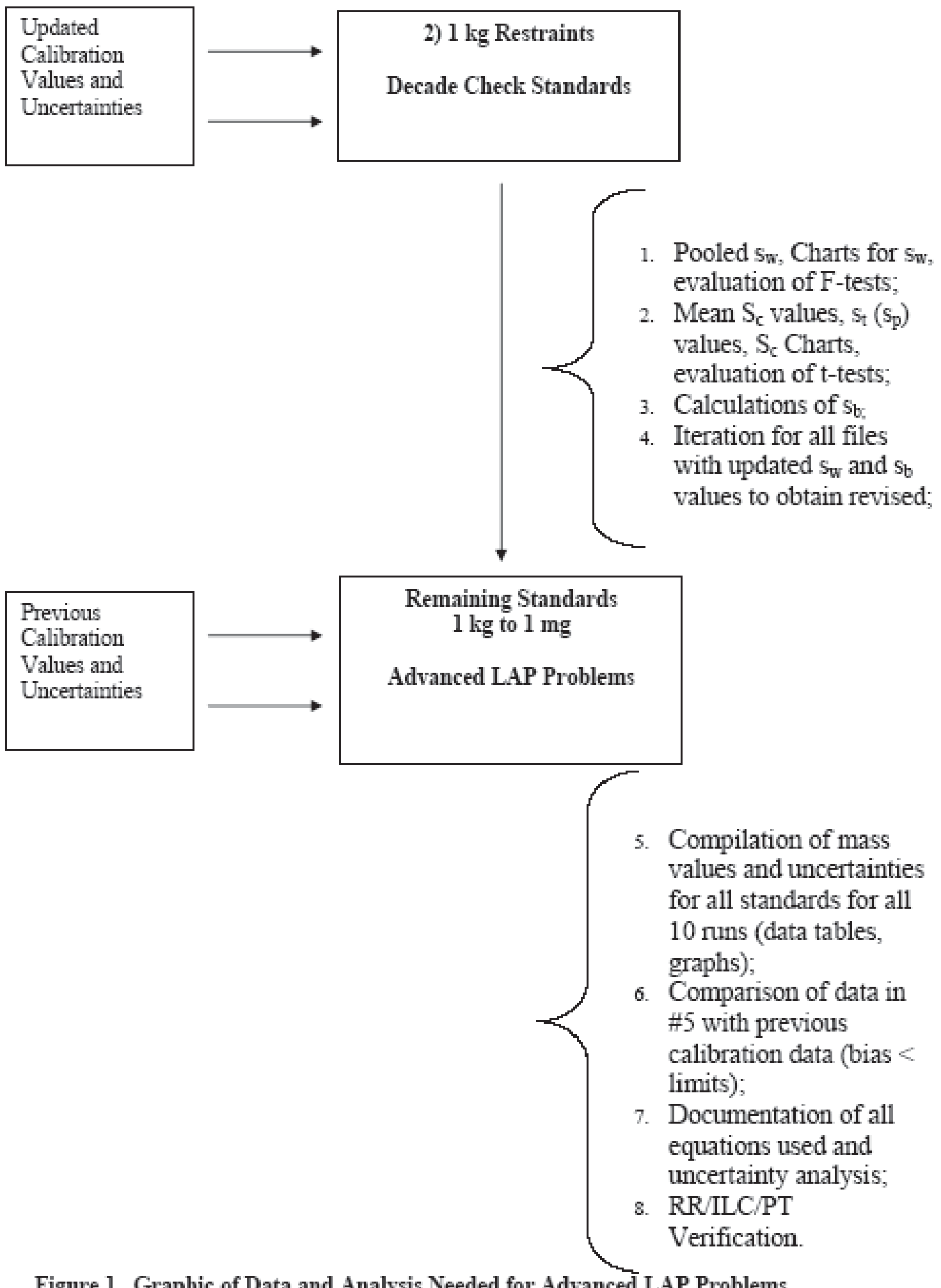

Figure 1. Graphic of Data and Analysis Needed for Advanced LAP Problems. 


\section{Mass Code Intercomparisons}

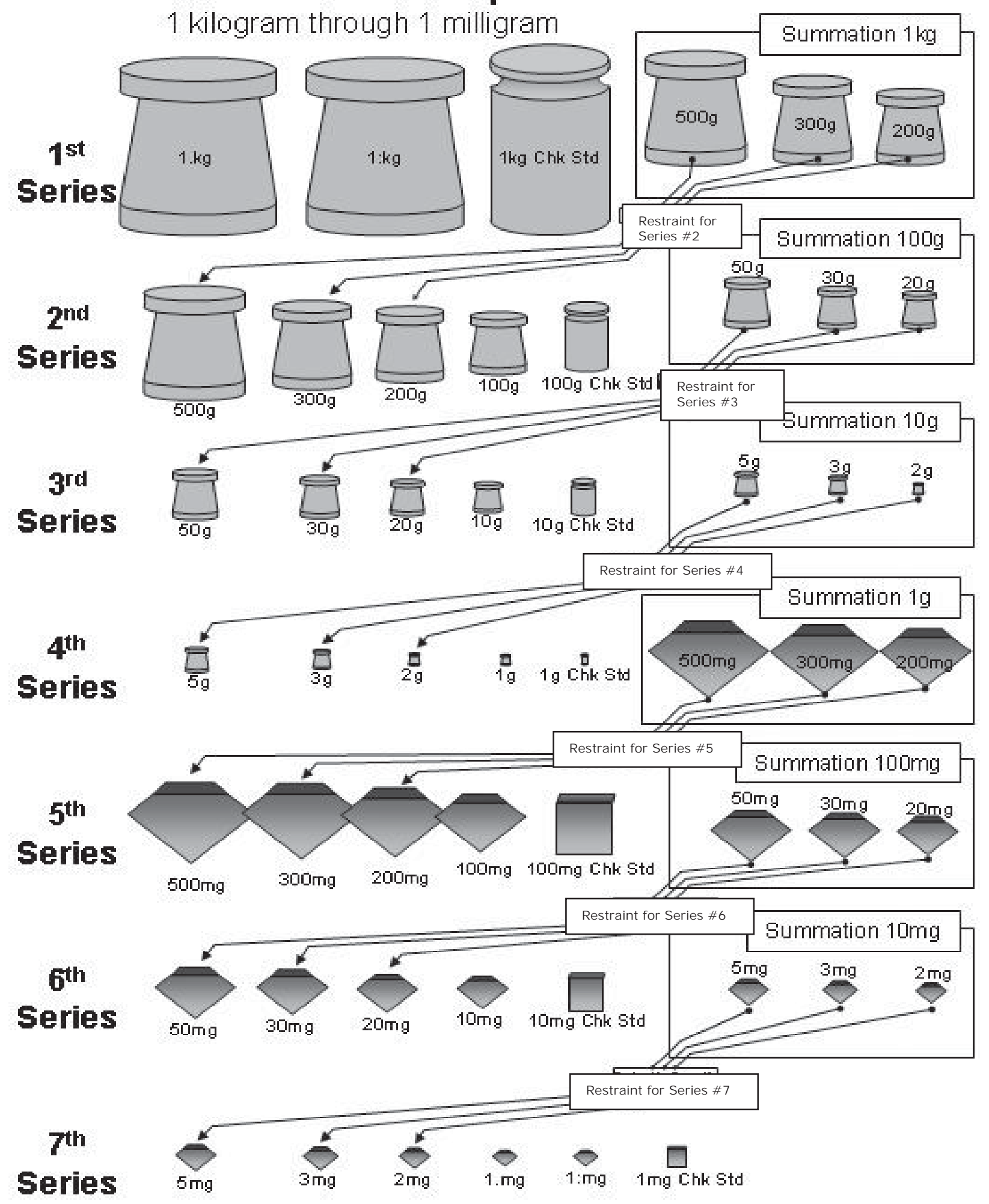


Series 1

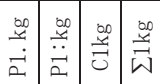

Measurement Matrix

$1 \mathrm{~kg}$ through $1 \mathrm{mg}$

\begin{tabular}{|c|c|c|c|c|c|}
\hline $1^{\text {st }}$ Double Sub & + & - & & & $1 \mathrm{~kg}$ load \\
\hline $2^{\text {nd }}$ Double Sub & + & & - & & $1 \mathrm{~kg} \mathrm{load}$ \\
\hline $3^{\text {rd }}$ Double Sub & + & & & - & $1 \mathrm{~kg}$ load \\
\hline $4^{\text {th }}$ Double Sub & & + & - & & $1 \mathrm{~kg} \mathrm{load}$ \\
\hline $5^{\text {th }}$ Double Sub & & + & & - & $1 \mathrm{~kg}$ load \\
\hline $6^{\text {th }}$ Double Sub & & & + & - & $1 \mathrm{~kg} \mathrm{load}$ \\
\hline
\end{tabular}

Series 2

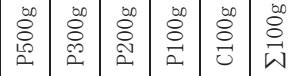

\begin{tabular}{|c|c|c|c|c|c|c|c|}
\hline $1^{\text {st }}$ Double Sub & + & - & - & + & - & & $600 \mathrm{~g}$ load \\
\hline $2^{\text {nd }}$ Double Sub & + & - & - & & + & - & $600 \mathrm{~g}$ load \\
\hline $3^{\text {rd }}$ Double Sub & + & - & - & - & & + & $600 \mathrm{~g}$ load \\
\hline $4^{\text {th }}$ Double Sub & + & - & - & & & & $500 \mathrm{~g}$ load \\
\hline $5^{\text {th }}$ Double Sub & + & & - & - & - & - & $500 \mathrm{~g}$ load \\
\hline $6^{\text {th }}$ Double Sub & & + & - & + & - & - & $400 \mathrm{~g}$ load \\
\hline $7^{\text {th }}$ Double Sub & & + & - & - & + & - & $400 \mathrm{~g}$ load \\
\hline $8^{\text {th }}$ Double Sub & & + & $\begin{array}{llllll}- & & & & & \end{array}$ & - & - & + & $400 \mathrm{~g}$ load \\
\hline $9^{\text {th }}$ Double Sub & & & + & - & - & & $200 \mathrm{~g}$ load \\
\hline $10^{\text {th }}$ Double Sub & & & + & - & & - & $200 \mathrm{~g}$ load \\
\hline $11^{\text {th }}$ Double Sub & & & + & & - & - & $200 \mathrm{~g}$ load \\
\hline Serie & $\stackrel{60}{20}$ & $\stackrel{b}{\varrho}$ & $\stackrel{\text { bo }}{\Sigma}$ & $\stackrel{\infty}{\simeq}$ & $\stackrel{\infty}{ు}$ & Ш & \\
\hline
\end{tabular}

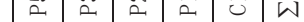

\begin{tabular}{|c|c|c|c|c|c|c|c|}
\hline $1^{\text {st }}$ Double Sub & + & - & - & + & - & & $6 \mathrm{~g} \mathrm{load}$ \\
\hline $2^{\text {nd }}$ Double Sub & + & - & - & & + & - & $6 \mathrm{~g}$ load \\
\hline $3^{\text {rd }}$ Double Sub & + & - & 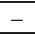 & - & & + & $6 \mathrm{~g} \mathrm{load}$ \\
\hline $4^{\text {th }}$ Double Sub & + & - & - & & & & $5 \mathrm{~g} 1 \mathrm{load}$ \\
\hline $5^{\text {th }}$ Double Sub & + & & - & - & - & - & $5 \mathrm{~g}$ load \\
\hline $6^{\text {th }}$ Double Sub & & + & - & + & - & - & $4 \mathrm{~g}$ load \\
\hline $7^{\text {th }}$ Double Sub & & + & - & - & + & - & $4 \mathrm{~g} \mathrm{load}$ \\
\hline $8^{\text {th }}$ Double Sub & & + & 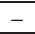 & 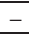 & - & + & $4 \mathrm{~g} \mathrm{load}$ \\
\hline $9^{\text {th }}$ Double Sub & & & + & - & - & & $2 \mathrm{~g}$ load \\
\hline $10^{\text {th }}$ Double Sub & & & + & - & & - & $2 \mathrm{~g}$ load \\
\hline $11^{\text {th }}$ Double Sub & & & + & & - & - & $2 \mathrm{~g} \mathrm{load}$ \\
\hline
\end{tabular}

Series 6

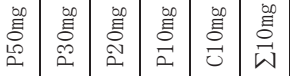

\begin{tabular}{|r|c|c|c|c|c|c|c|}
\hline $1^{\text {st }}$ Double Sub & + & - & - & + & - & & $60 \mathrm{mg}$ load \\
\hline $2^{\text {nd }}$ Double Sub & + & - & - & & + & - & $60 \mathrm{mg}$ load \\
\hline $3^{\text {rd }}$ Double Sub & + & - & - & - & & + & $60 \mathrm{mg}$ load \\
\hline $4^{\text {th }}$ Double Sub & + & - & - & & & & $50 \mathrm{mg} \mathrm{load}$ \\
\hline $5^{\text {th }}$ Double Sub & + & & - & - & - & - & $50 \mathrm{mg} \mathrm{load}$ \\
\hline $6^{\text {th }}$ Double Sub & & + & - & + & - & - & $40 \mathrm{mg} \mathrm{load}$ \\
\hline $7^{\text {th }}$ Double Sub & & + & - & - & + & - & $40 \mathrm{mg} \mathrm{load}$ \\
\hline $8^{\text {th }}$ Double Sub & & + & - & - & - & + & $40 \mathrm{mg} \mathrm{load}$ \\
\hline $9^{\text {th }}$ Double Sub & & & + & - & - & & $20 \mathrm{mg} \mathrm{load}$ \\
\hline $10^{\text {th }}$ Double Sub & & & + & - & & - & $20 \mathrm{mg} \mathrm{load}$ \\
\hline $11^{\text {th }}$ Double Sub & & & + & & - & - & $20 \mathrm{mg} \mathrm{load}$ \\
\hline
\end{tabular}

Series 3

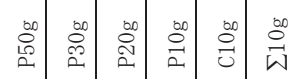

\begin{tabular}{|r|c|c|c|c|c|c|c|}
\hline $1^{\text {st }}$ Double Sub & + & - & - & + & - & & $60 \mathrm{~g}$ load \\
\hline $2^{\text {nd }}$ Double Sub & + & - & - & & + & - & $60 \mathrm{~g}$ load \\
\hline $3^{\text {rd }}$ Double Sub & + & - & - & - & & + & $60 \mathrm{~g}$ load \\
\hline $4^{\text {th }}$ Double Sub & + & - & - & & & & $50 \mathrm{~g}$ load \\
\hline $5^{\text {th }}$ Double Sub & + & & - & - & - & - & $50 \mathrm{~g}$ load \\
\hline $6^{\text {th }}$ Double Sub & & + & - & + & - & - & $40 \mathrm{~g}$ load \\
\hline $7^{\text {th }}$ Double Sub & & + & - & - & + & - & $40 \mathrm{~g}$ load \\
\hline $8^{\text {th }}$ Double Sub & & + & - & - & - & + & $40 \mathrm{~g}$ load \\
\hline $9^{\text {th }}$ Double Sub & & & + & - & - & & $20 \mathrm{~g}$ load \\
\hline $10^{\text {th }}$ Double Sub & & & + & - & & - & $20 \mathrm{~g}$ load \\
\hline $11^{\text {th }}$ Double Sub & & & + & & - & - & $20 \mathrm{~g}$ load \\
\hline
\end{tabular}

Series 5

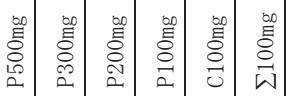

\begin{tabular}{|r|c|c|c|c|c|c|c|}
\hline $1^{\text {st }}$ Double Sub & + & - & - & + & - & & $600 \mathrm{mg}$ load \\
\hline $2^{\text {nd }}$ Double Sub & + & - & - & & + & - & $600 \mathrm{mg}$ load \\
\hline $3^{\text {rd }}$ Double Sub & + & - & - & - & & + & $600 \mathrm{mg} \mathrm{load}$ \\
\hline $4^{\text {th }}$ Double Sub & + & - & - & & & & $500 \mathrm{mg}$ load \\
\hline $5^{\text {th }}$ Double Sub & + & & - & - & - & - & $500 \mathrm{mg} \mathrm{load}$ \\
\hline $6^{\text {th }}$ Double Sub & & + & - & + & - & - & $400 \mathrm{mg} \mathrm{load}$ \\
\hline $7^{\text {th }}$ Double Sub & & + & - & - & + & - & $400 \mathrm{mg} \mathrm{load}$ \\
\hline $8^{\text {th }}$ Double Sub & & + & - & - & - & + & $400 \mathrm{mg} \mathrm{load}$ \\
\hline $9^{\text {th }}$ Double Sub & & & + & - & - & & $200 \mathrm{mg} \mathrm{load}$ \\
\hline $10^{\text {th }}$ Double Sub & & & + & - & & - & $200 \mathrm{mg} \mathrm{load}$ \\
\hline $11^{\text {th }}$ Double Sub & & & + & & - & - & $200 \mathrm{mg} \mathrm{load}$ \\
\hline
\end{tabular}

Series 7

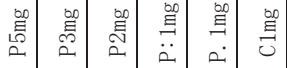

\begin{tabular}{|r|c|c|c|c|c|c|c|}
\hline $1^{\text {st }}$ Double Sub & + & - & - & + & - & & $6 \mathrm{mg}$ load \\
\hline $2^{\text {nd }}$ Double Sub & + & - & - & & + & - & $6 \mathrm{mg}$ load \\
\hline $3^{\text {rd }}$ Double Sub & + & - & - & - & & + & $6 \mathrm{mg} \mathrm{load}$ \\
\hline $4^{\text {th }}$ Double Sub & + & - & - & & & & $5 \mathrm{mg} \mathrm{load}$ \\
\hline $5^{\text {th }}$ Double Sub & + & & - & - & - & - & $5 \mathrm{mg} \mathrm{load}$ \\
\hline $6^{\text {th }}$ Double Sub & & + & - & + & - & - & $4 \mathrm{mg} \mathrm{load}$ \\
\hline $7^{\text {th }}$ Double Sub & & + & - & - & + & - & $4 \mathrm{mg} \mathrm{load}$ \\
\hline $8^{\text {th }}$ Double Sub & & + & - & - & - & + & $4 \mathrm{mg} \mathrm{load}$ \\
\hline $9^{\text {th }}$ Double Sub & & & + & - & - & & $2 \mathrm{mg} \mathrm{load}$ \\
\hline $10^{\text {th }}$ Double Sub & & & + & - & & - & $2 \mathrm{mg} \mathrm{load}$ \\
\hline $11^{\text {th }}$ Double Sub & & & + & & - & - & $2 \mathrm{mg} \mathrm{load}$ \\
\hline
\end{tabular}

\section{Establishing Measurement Controls}

\section{Process Evaluation}

For each combination of a weighing design, specific load, and specific balance (e.g., a 4-1 design, at a $1 \mathrm{~kg}$ load, on serial number \#\#\#\# balance), a measurement control process should be defined and data collected to characterize both the standard uncertainty of the process, $\mathrm{s}_{\mathrm{w}}$, and the standard uncertainty for the standard over time, $\mathrm{s}_{\mathrm{t}}$. These values are essential for correctly reducing measurement data and calculating the uncertainty assigned to each mass value in a report. This process is more than simple statistical process control because the process is evaluated with an F-test 
in each series and assigned values for the standards and check standards are verified for accuracy with each run using a t-test.

In a surveillance test of reference/working standards from $1 \mathrm{~kg}$ to $1 \mathrm{mg}$, there are seven series as characterized below (a 5-2-2-1 set of standards may be substituted for the 5-3-2-1 set):

Table 2. Example Weighing Designs.

\begin{tabular}{||l|l|l|}
\hline \multicolumn{1}{|c|}{ Series } & \multicolumn{1}{|c|}{$\begin{array}{c}\text { Weighing Design } \\
\text { (Tech Note } 952)\end{array}$} & \multicolumn{1}{c|}{ Decade Load } \\
\hline \hline 1 & A.1.2(1, $1,1,1)(4-1)$ & $1 \mathrm{~kg}$ \\
\hline 1 A (option) & A.1.4 $(1,1,1,1,1)(5-1)$ & $1 \mathrm{~kg}$ \\
\hline 2 & C.2 $(5,3,2,1,1,1)$ & $600,500,400,200 \mathrm{~g}$ \\
\hline$($ optional) & A.1.2 or A.1.4 & $100 \mathrm{~g}$ \\
\hline 3 & C.2 $(5,3,2,1,1,1)$ & $60,50,40,20 \mathrm{~g}$ \\
\hline 4 & C.2 $(5,3,2,1,1,1)$ & $6,5,4,2 \mathrm{~g}$ \\
\hline 5 & C.2 $(5,3,2,1,1,1)$ & $600,500,400,200 \mathrm{mg}$ \\
\hline 6 & C.2 $(5,3,2,1,1,1)$ & $60,50,40,20 \mathrm{mg}$ \\
\hline 7 & C.1 $(5,3,2,1,1)$ or C.2 & $6,5,3,2,1 \mathrm{mg}$ \\
\hline \hline
\end{tabular}

NOTE: When data is reduced using the Mass Code, switching balances within a series may result in artificially low process standard deviations and will result in errors in between-time calculations.

As noted earlier, the Advanced LAP problems are the minimum recommendations for collecting data that will begin to characterize the measurement process. Ten complete runs on the reference/working standards, $1 \mathrm{~kg}$ through $1 \mathrm{mg}$ (all seven series reduced using the Mass Code), must be made. An additional series at a $100 \mathrm{~g}$ load is essential to establish a secondary starting point for the calibration of $100 \mathrm{~g}$ kits. This means that initial data will be collected for at least these eight series.

The section on Calculations in SOP No. 28 or the Excel job aid show how to calculate each of the standard uncertainty values that should be entered in the Mass Code data file once data from the initial ten runs is available. Meanwhile, because statistical data for the new process and check standards may be unavailable, simulated values, based on knowledge of each measurement process, may be used in order for the Mass Code to reduce data. For the first ten runs, process standard deviation values, based on previous three-ones (also called three in one, abbreviated 3-1) weighing designs or multiple double substitutions for each balance are satisfactory. Using this process, only the size of the uncertainties and the statistical tests will be affected when data is reduced; the mass values are not affected. However, once actual data is available, the simulated data in the data file must be replaced, and final reports generated. All reports should be considered as "draft” during the 
process of gathering the initial data; the statistics and uncertainty values must be updated prior to performing the final data analysis.

Proper characterization of the measurement process is more critical when using advanced weighing designs in decade series with the Mass Code than when using routine mass comparisons with one-to-one standards. This is primarily because the statistics used by the Mass Code distribute the uncertainty from the starting restraint (reference standard) proportionally among all the weights in each series. Also, the standard uncertainty of the process (previously called random error) is distributed among all the weights in each particular series. This type of data reduction allows the Mass Code to assign smaller uncertainties; however, the validity of these uncertainties is very dependent upon a well-characterized measurement process. A major difference between advanced weighing designs using the Mass Code, and routine calibrations such as the 3-1 weighing design and the double substitution, is that the Mass Code uses the uncertainty of the starting restraint only. The 3-1 design and the double substitution use the uncertainty of a standard(s) at each denomination. In a $1 \mathrm{~kg}$ to $1 \mathrm{mg}$ Mass Code calibration, the starting restraint portion of the uncertainty is distributed among all other denominations and soon becomes negligible around five grams. Therefore, weights below five grams are primarily dependent upon the standard uncertainty of the process when assigning an uncertainty to a test weight.

\section{Data Input}

The [1993] FORTRAN version of the Mass Code required input for statistical measurement control parameters in four locations:

1) Line eight: "ran err" or "random error" for the standard is entered first; this hasn't been used and zero must be entered;

2) Line eight: "sys err" or "systematic error" for the standard, $\mathrm{s}_{\mathrm{r}}$, is entered second; this value is taken from the [NIST] calibration report and should be divided by the coverage factor, $k$, that was used in reporting the uncertainty (see calculations in SOP No. 28 for formula to be used when using more than one restraint);

3) Line thirteen: the within-process standard deviation is the same as the standard uncertainty of the process, $\mathrm{s}_{\mathrm{w}}$. This value is used for the F-test and is entered at the beginning of line thirteen on the first series (at the beginning of the line that contains the sensitivity weight data for subsequent series). The value is based on pooled data for observed standard deviations for the process (see calculations in SOP No. 28 for formula to be used); and

4) Line thirteen: the between-time standard deviation, $\mathrm{s}_{\mathrm{b}}$, is entered at the end of line thirteen on the first series (at the end of the line that contains sensitivity weight data for subsequent series) and is the calculated value that measures the variation of the value for the check standard over time, $\mathrm{s}_{\mathrm{t}}$, less the contribution from the standard uncertainty of the process (see the calculations in SOP No. 28 for formula to be used.)

In Lab Wizard 1.0, the C++, Windows version of the Mass Code (prior to Windows 7, 64 bit), these four parameters are identified in the data entry area called "Description of Weights." They are identified in Restraint Specifications and Statistical Parameters sections as: "Random error," 
"Systematic error," "Standard deviation," and "Between std. dev.". These items correspond exactly to the FORTRAN version of the Mass Code and are entered in the same location in the data file.

NOTE: Both the FORTRAN and Lab Wizard 1.0 versions of the mass calibration software have been modified to conform to the NIST policy on uncertainty (see NIST Technical Note 1297) as far as possible. References to "systematic error" have been changed to "type B uncertainty"; references to "random error" have been changed to "type A uncertainty"; and references to "uncertainty" have been changed to "expanded uncertainty." The type B uncertainties are calculated as one standard deviation estimates for systematic error, and the type A uncertainties are calculated as one standard deviation estimates for random error. The expanded uncertainties are calculated as the root sum squares of the type A and type B uncertainties multiplied by a coverage factor of two.

However, to preserve the integrity of the statistical control procedure for mass calibrations, the operation of the Mass Code deviates from the NIST policy in the evaluation of type A and type B uncertainties. The policy defines type A (random) uncertainties in a global manner; i.e., as a function of both local phenomena (balance precision and long-term measurement precision) and hierarchical phenomena (uncertainties associated with previously assigned values of reference standards). The test for statistical control for each series requires a standard deviation based only on local phenomena. The Mass Code does not distinguish between these two requirements, and it will produce an improper t-test if the hierarchical uncertainties are treated as random components. The solution to this conflict is to distinguish between local and hierarchical uncertainties and to define hierarchical uncertainties as type B uncertainties. ${ }^{6}$

Handling the Output

To establish measurement controls once the Mass Code has been run, certain data must be extracted from each series and placed in a spreadsheet or database for storage, analysis, and measurement assurance:

Test Number;

Operator ID;

Date of Test;

Balance ID;

Restraint ID;

Check Standard ID;

Check Standard Nominal Value;

Starting Restraint Number;

Calibration Design ID;

Average Corrected Temperature in Degrees C;

Average Corrected Pressure in Pascal;

Average Corrected Humidity in Percent;

Average Computed Air Density in $\mathrm{mg} / \mathrm{cm}^{3}$;

Observed Standard Deviation of the Process;

$6 \quad$ Croarkin, M. C., Internal NIST Correspondence, July \& August 1993. 
Accepted Standard Deviation of the Process;

Degrees of Freedom;

F-Ratio;

Observed Correction of the Check Standard;

Accepted Mass Correction of the Check Standard;

t-Value; and

Expanded Uncertainty assigned to the Check Standard.

When either version of the Mass Code is run, it produces two files, one called "control" and one called "statis." The "control" file contains a string of data for each series that contains: the month, day, year, check standard identification, observed value for the check standard, balance identification, process standard deviation, degrees of freedom, weighing design identification, average temperature, range of temperature during the measurement, average pressure, range of pressure during the measurement, average humidity, range of humidity during the measurement, air density, range of air density during the measurement, operator identification, and a flag for process control results ( 0 = ok; a number 1 , 2, or 3 (depending on the version of the Mass Code used) flags that the check standard failed, the observed standard deviation failed, or both failed). This file can be imported to a spreadsheet using a parse function so that each item is entered into a separate cell and saved. The "statis" file contains F-test and t-test data for each series run in the Mass Code. Unless an assignable blunder is detected in the data, all out of control series must be saved in the control chart file or the statistical limits will gradually become artificially small resulting in an increased number of failed tests.

Each of these files should be saved by another name and/or in another directory immediately after each run of the Mass Code because the data is not cumulatively saved. These files contain information for the preceding Mass Code reduction only, and are written over with each run of the Mass Code.

\section{Reviewing Mass Code Reports}

Several sections within the Mass Code report must be reviewed for adequacy. Key areas are observation values, the F-test, and the t-test. If unusually high t-test or F-test values are observed, one should check for data entry errors first.

Evaluate the F-test to make sure that the observed standard deviation agrees statistically with the accepted standard deviation of the process. An F-value is quoted and immediately below this value in the report is a statement that shows whether the F-test passed or failed.

Evaluate the t-test to verify that the observed mass correction of the check standard agrees statistically with the accepted mass correction of the check standard. A t-value is quoted and immediately below the t-value in the report is a statement that says whether the check standard is in-control or out-of-control.

Should either test fail and no data-entry errors are found, the series should be rerun. If the process is gradually changing, the t-values or F-values will usually fall in a range from two to nine. If statistical data is graphed properly, trends can be identified before they become critical. If many tests 
fail, it could suggest a change in the measurement process in which case the data is combined with the other data to define the new measurement parameters. If failed data with no attributable errors is routinely and incorrectly discarded, statistical limits will be artificially reduced. Uncertainty values based on such data will be invalid.

\section{Graphs and Control Charts}

\section{Critical Graphs}

Standard Control Charts - When advanced mass calibrations are used for surveillance testing, each weight (500 g to $1 \mathrm{mg}$ ) involved may be graphed separately. These data and charts can be used to verify calibration values and to determine appropriate calibration intervals. When appropriate for reference/working standards, a new accepted value may be calculated as either the mean of all values, or the predicted value from the linear fit of the data at a time six months in the future.

When the measurement process has been sufficiently characterized and advanced mass calibrations are used for routine calibrations, a graph must be prepared for the check standard at each decade to properly characterize each measurement process. Analysis of the data provides the statistics for calculating the between-time standard deviations and can be used to verify standard and check standard values. The standard deviation over time is calculated from either the standard deviation about the mean, or the residual standard deviation from the linear fit. The standard deviation is later compared with the process deviation to detect if there is a between-time component of error in the measurement process. As noted for surveillance testing, the accepted values can be calculated in one of two ways.

Measurements and control charts for two external or "monitoring" $1 \mathrm{~kg}$ check standards are recommended to verify the calibration values for the two $1 \mathrm{~kg}$ reference standards. Measurements are made between these two external standards and the reference standards using a 4-1 or 5-1 weighing design. The external kilogram standards may be part of a circulating mass package with recent NIST calibration (as used in proficiency testing) or may be maintained in the laboratory but must receive less frequent (less than $25 \%$ as often) use than the reference standards. Analysis of calibration results over time as recorded on control charts can provide a realistic estimate of calibration uncertainty and allow the investigation of drift for standard values due to time and use. Historical analysis can also help set calibration intervals.

Process charts - Control charts for the process standard deviation (for each series/balance) are used to establish process variability and an accepted within-process standard deviation, $\mathrm{s}_{\mathrm{w}}$; each point can note the degrees of freedom differentiating between series. Standard deviations for each balance are plotted versus time. Plots are critiqued for outliers and degradation. A new accepted value is calculated by pooling the standard deviation for each balance.

\section{Optional Graphs}

Summation Graphs - With a measurement control program in place for 3-1 weighing designs that shows the values for summations of standards, data from the Mass Code reports may be plotted with those values (when the 3-1 design uses the summation as the check standard). A number of items should be plotted versus time: the mean for the 3-1 summation values, the upper and lower 
control/warning limits, the Mass Code summation values and uncertainties, and a line showing the NIST calibration value. This graph may look cluttered, but it provides enormous insight to the relationships between the NIST value, the Mass Code values, and the 3-1 values for the same group of weights. It also provides a comparison between the separate measurement processes. The 3-1 values may show greater precision than the Mass Code values. This is because in some cases the 3-1 values may be assigned using a balance with a lower standard deviation of the process than the balance used for the Mass Code.

F-values - Graphing the F-values for a particular series can show trends in the process and can evaluate the appropriateness of the assigned process parameters. The F-values are plotted chronologically with the mean. The graph should be analyzed for trends and for uniform distribution above and below the F-value of 1.00 .

t-values - Graphing the t-values of each series allows visualization of the extent of agreement between the observed and accepted value of the check standard. It also permits a comparison with the current measurement process. The t-values are plotted chronologically with the mean. The graph should be analyzed for trends and for uniform distribution above and below the t-value of 1.00.

\section{Proficiency Tests}

Interlaboratory comparisons (proficiency tests) need to be conducted at least once every four years at the advanced level and may consist of two kits with an entire set of standards: 1 kg through 1 mg to enable Youden-type analyses. Proficiency testing reports and results are prepared using OWM template reports and approved by NIST prior to final distribution and reporting. Proficiency test results provide useful information about potential errors in the laboratory, about the uncertainty reported, and about drift of artifacts during the intercomparisons. This information provides opportunity for evaluating a laboratory's capability to meet stated uncertainties.

\section{Evaluation Criteria for Proficiency Tests}

Verification of the Reference Value

The Reference value will be verified by using the OWM procedures for selecting the Reference value. Whenever possible, Reference values for Proficiency Tests will be based on calibrations from a National Metrology Institute.

The normalized error ( $\left.E_{n}\right)$ concept (which is used internationally) is used to evaluate the submitted value for each laboratory. The normalized error is a ratio of the difference between the observed and accepted values and the combined uncertainty ( $\mathrm{at} k=2$ ) in the process combined by the root sum square method. 
Verification of Laboratory Values

After verification of the Reference value, the following Normalized Error $\left(E_{n}\right)$ formula is used to evaluate the acceptance of each laboratory value (NVLAP Handbook 150, Procedures and General Requirements.):

$$
E_{n}=\left|\frac{\left(\text { Lab }_{\text {value }}-N I S T_{\text {value }}\right)}{\sqrt{\left(\text { Lab unc }^{2}+N I S T_{\text {unc }}^{2}\right)}}\right|
$$

$\mathrm{E}_{\mathrm{n}}$ calculated for a laboratory must be less than one to pass this test. The laboratory uncertainty and the reference value uncertainty are calculated at a $95 \%$ confidence level.

Verification of the Laboratory Precision

This criterion evaluates and validates the reported uncertainty of the laboratory for its suitability to the level against which the laboratory is being evaluated. At the highest level of mass calibration, the uncertainty assigned by the participating laboratory should be less than the tolerance. There are several perspectives regarding the use of tolerance and uncertainty ratios; this is only a general guideline and is not intended to be a requirement. However, if the laboratory will determine compliance to OIML or ASTM standards, the expanded uncertainty at $k=2$, must be less than $1 / 3$ of the applicable tolerance.

$$
U_{l a b}<\text { Tolerance OR } U_{l a b}<\text { Tolerance/3 }
$$

NOTE: Criteria for determining satisfactory/unsatisfactory compliance for proficiency tests may be revised in the future to handle uncertainties based on $95 \%$ confidence intervals rather than $99.7 \%$ confidence intervals.

\section{File Management}

Mass Code reports that have been generated and printed do not need to be saved on a hard disk; they can take up valuable space on the computer. Instead, a directory may be created to store each data file. Data files take up little disk space and the complete report can be generated as needed.

Once the ten basic runs are made on the standards (LAP Problem 1) and the process parameters are defined, the original data files must be updated with the observed process parameters (to replace simulated data with observed data), and final reports can be generated. These new reports will contain the same mass values, but the quoted uncertainties will reflect the true process more closely. 


\section{Software Management}

\section{Distribution}

Mass Code has often been distributed by the NIST Office of Weights and Measures upon acceptable completion of the Advanced Mass Metrology seminar. Lab Wizard software was "personalized” for each laboratory: the name of the laboratory and of the metrologist is embedded in the software and reports are generated containing the name of the laboratory and the metrologist.

\section{Licensing and Software Quality Assurance}

Each copy of Mass Code software distributed by OWM will be serialized, and a list of trained metrologists and their laboratories is maintained. All practical steps have been taken at NIST to ensure correct results when the software is used with proper data files. However, each laboratory must verify this independently and must document the verification. Each licensee must agree to refrain from copying or transferring software to others who have not participated in Advanced Mass training. OWM will only provide technical support to metrologists who have participated in the Advanced Mass training from the NIST Office of Weights and Measures.

\section{Software Updates}

The Mass Code will be periodically updated and new versions will be released to trained metrologists when available.

Approved Weighing Designs

The Office of Weights and Measures recognizes a variety of weighing designs such as those found in NBS Technical Notes 844 and 952, and the NIST/SEMATECH e-Handbook. However, weighing designs are used throughout the world with variations from those presented in NIST publications. Metrologists should use good judgment in developing unusual weighing designs and may submit them to NIST for review or validation whenever appropriate. Any designs submitted to NIST for review should be accompanied by sufficient experimental data to provide adequate evaluation. Metrologists should consider, and be able to justify, variations in weighing designs, the selection and use of check standards, length of designs and time restraints particularly with respect to drift, selection of balance, use of sensitivity weights, etc., to suit particular calibration applications. With the use of electronic mass comparators, length of time during a design and fatigue of the operator (which affect design selection) are of less concern than with the older mechanical balances. When developing new designs, another consideration should be that weights of equal nominal values should have the same uncertainty. NIST/OWM strongly recommends designs that incorporate check standards for process and standard verification.

Any unusual weighing designs not submitted to NIST for review will be subject to critical review during on-site assessments and may not be used in support of traceability hierarchies without suitable outside review, validation, and approval. 


\section{Documentation of Standard Operating Procedures}

To help with laboratory compliance to NIST Handbook 143, NVLAP Handbook 150 and ISO/IEC 17025, SOP No. 28 "Recommended Standard Operating Procedures for Using Advanced Weighing Designs” was developed and is included with this update as an appendix.

\section{Metrological Traceability and Calibration Intervals}

Ensuring metrological traceability and providing documentation of how metrological traceability is maintained is a critical concern for customers and for accreditation bodies when evaluating a laboratory. Metrological traceability for mass measurements can be maintained through two reference kilograms that have been calibrated at NIST as long as appropriate mass calibration and measurement assurance procedures are used (and documented). The process described in this document provides guidance for laboratories on how to maintain adequate metrological traceability with sufficiently small uncertainties to meet the laboratory and customer requirements. See GMP 11 and GMP 13 for additional examples of traceability hierarchies and calibration interval requirements. Each laboratory must have an implementation policy that covers the requirements in GMP 11 and GMP 13 to ensure metrological traceability with appropriate uncertainties and calibration intervals. Both of these GMPs are posted on the NIST website.

The assigned LAP problems can be used to initiate an appropriate measurement assurance program and prepare graphs. The data from the analysis and preparation of the graphs must be evaluated against original NIST values for the reference/working mass standards and check standards as appropriate. Additional data collected periodically is added to the original graphs. Data should be updated periodically and evaluated. How often data are updated depends on the laboratory workload.

Each laboratory must document which standards are used at each level in their traceability hierarchy process, what specific measurement assurance is in place at each step, and how often intercomparisons are conducted. The measurement assurance program, as described, is fully integrated into the actual calibration process. Therefore, this is not an exercise used to provide data for an accreditation body, but actually provides checks on the system that the laboratory can use to ensure that each measurement performed for a customer is accurate and traceable with validated measurement results and uncertainties.

It is critical for laboratories to participate in interlaboratory comparisons that provide periodic checks on the measurement process. The data must be correlated with the measurement assurance program to be meaningful. Any discrepancies indicate the need for further investigation and possible need for calibration of the reference standards. Laboratories must participate in this level of intercomparison on a frequency no greater than four years (per OWM policy published in NISTIR 7082, Proficiency Test Policy and Plan (for State Weights \& Measures Laboratories), G. Harris and J. Gust, January 2004.) 


\section{Formulae and Calculations}

The following items are calculated using formulae located in SOP No. 28 "Recommended Standard Operating Procedure for Using Advanced Weighing Designs” which is included in this edition as an appendix.

- $\mathrm{s}_{\mathrm{r}}-$ The standard uncertainty of the starting restraint in the first series.

- $\mathrm{s}_{\mathrm{w}}$ - The within-process standard deviation.

- $\mathrm{s}_{\mathrm{b}}$ - The between-time standard deviation for each particular series.

- Effective densities for summation standards.

- Effective cubical coefficients of expansion for summation standards.

SOP 5 is inserted here as Appendix A for printing only; it is kept separate from the document for website downloads. SOP 28 is inserted here as Appendix B for printing only; it is kept separate from the document for website downloads. 


\section{SOP 5}

\section{Recommended Standard Operating Procedure \\ for}

Using a 3-1 Weighing Design

1. Introduction

\subsection{Purpose}

The 3-1 weighing design is a combination of three double substitution comparisons of three weights of equal nominal value; a standard, an unknown weight, and a second standard called a check standard. (The check standard may be made up of a summation of weights.) The weights are compared using an equal-arm, single-pan mechanical, full electronic, or a combination balance utilizing built-in weights and a digital indication. The specific SOP for the double substitution procedure for each balance is to be followed. The 3-1 weighing design provides two methods of checking the validity of the measurement using an integrated F-test to monitor the within process standard deviation and a t-test to evaluate the stability of the standard and check standard. Hence, the procedure is especially useful for high accuracy calibrations for weights in $\mathrm{OIML}^{1}$ Classes $\mathrm{E}_{2}$ to $\mathrm{F}_{2}$ and $\mathrm{ASTM}^{2}$ Classes 0 and 1 , in which it is critical to assure that the measurements are valid and well documented. This procedure is recommended as a minimum for precision calibration of laboratory working standards that are subsequently used for lower level calibrations and for routine calibration of precision mass standards used for balance calibration. For surveillance of reference standards, such as OIML $E_{1}$, ASTM 00 or better, working standards, and for calibration of precision mass standards used to calibrate other mass standards, see SOP 28 for the use of higher level weighing designs.

\subsection{Prerequisites}

1.2.1. Verify that valid calibration certificates with appropriate values and uncertainties are available for all of the standards used in the calibration. All standards must have demonstrated metrological traceability to the international system of units (SI), which may be through a National Metrology Institute such as NIST.

1.2.2. Standards must be evaluated to ensure that standard uncertainties for the intended level of calibration are sufficiently small. Reference standards should only be used to calibrate the next lower level of working standards in the laboratory and should not be used to routinely calibrate customer standards.

${ }^{1}$ OIML is the International Organization for Legal Metrology. Weight classes are published in OIML R111, which is freely available at http://www.oiml.org.

${ }^{2}$ ASTM International (formerly the American Society for Testing and Materials) publishes the E617 standard for mass specifications and tolerances. 
1.2.3. The balance that is used must be in good operating condition with sufficiently small process standard deviation as verified by F-test values, pooled short term standard deviations, and by a valid control chart for check standards or preliminary experiments to ascertain its performance quality when new balances are put into service.

1.2.4. The operator must be experienced in precision weighing techniques. The operator must have specific training in SOP 2, SOP 4, SOP 5, SOP 29, and be familiar with the concepts in GMP 10.

1.2.5. Verify that the laboratory facilities comply with the following minimum conditions to meet the expected uncertainty possible with this procedure and to comply with the balance manufacturer's operating conditions specified for the balance. Equilibration of balances and weights requires environmental stability of the laboratory within the stated limits for a minimum of 24 hours before a calibration.

Table 1. Environmental conditions.

\begin{tabular}{|c|c|c|}
\hline Echelon $^{3}$ & Temperature Requirements During a Calibration & $\begin{array}{l}\text { Relative Humidity } \\
\qquad(\%)\end{array}$ \\
\hline \multirow{2}{*}{ I } & $\begin{array}{c}\text { OIML } \mathrm{E}_{1}, \text { ASTM } 000,00,0 \\
\text { Lower and upper limits: } 18^{\circ} \mathrm{C} \text { to } 23{ }^{\circ} \mathrm{C} \\
\text { Maximum changes: } \pm 0.5^{\circ} \mathrm{C} / 12 \mathrm{~h} \text { and } \pm 0.3^{\circ} \mathrm{C} / \mathrm{h}\end{array}$ & \multirow{2}{*}{40 to $60 \pm 5 / 4 h$} \\
\hline & $\begin{array}{c}\text { OIML } \mathrm{E}_{2}, \mathrm{ASTM} 1 \\
\text { Lower and upper limits: } 18^{\circ} \mathrm{C} \text { to } 23{ }^{\circ} \mathrm{C} \\
\text { Maximum changes: } \pm 1{ }^{\circ} \mathrm{C} / 12 \mathrm{~h} \text { and } \pm 0.7^{\circ} \mathrm{C} / \mathrm{h}\end{array}$ & \\
\hline II & $\begin{array}{l}\text { Lower and upper limits: } 18^{\circ} \mathrm{C} \text { to } 23^{\circ} \mathrm{C} \\
\text { Maximum changes: } \pm 2{ }^{\circ} \mathrm{C} / 12 \mathrm{~h} \text { and } \pm 1.5^{\circ} \mathrm{C} / \mathrm{h}\end{array}$ & 40 to $60 \pm 10 / 4 h$ \\
\hline
\end{tabular}

1.2.5.1.It is important that the difference in temperature between the weights and the air inside the mass comparator is as small as possible. Keeping the reference weight and the test weight inside, or next to, the mass comparator before and during the calibration can reduce this temperature difference. Standards and test artifacts must be allowed to reach equilibration in or near the balance before starting measurements.

2. Methodology

2.1. Scope, Precision, Accuracy

3 Echelon I corresponds to weights of Classes OIML $\mathrm{E}_{1}$ and $\mathrm{E}_{2}$, Echelon II corresponds to weights of Classes OIML $\mathrm{F}_{1}$ and $\mathrm{F}_{2}$. 
This method can be performed on any type of balance using the appropriate double substitution SOP for the particular balance. Because considerable effort is involved, this weighing design is most useful for calibrations of the highest accuracy. The weighing design uses three double substitutions to calibrate a single unknown weight. This introduces redundancy into the measurement process and permits two checks on the validity of the measurement; one on accuracy and stability of the standard and the other on process repeatability. A least-squares best fit analysis is done on the measurement outputs to assign a value to the unknown weight. The standard deviation of the process depends upon the resolution of the balance and the care exercised to make the required weighings. The accuracy will depend upon the accuracy and uncertainty of the calibration of the standard weights and the precision of the comparison.

\subsection{Summary}

A standard weight, $\mathrm{S}$, an unknown weight, $\mathrm{X}$, and a check standard, $\mathrm{S}_{\mathrm{c}}$, are intercompared in a specific order using several double substitution processes. The balance and the weights must be prepared according to the appropriate double substitution SOP for the particular balance being used. Once the balance and weights have been prepared, all readings must be taken from the reading scale of the balance without adjusting the balance or weights in any way. Within a double substitution all weighings are made at regularly spaced time intervals to minimize effects due to instrument drift. The 3-1 weighing design includes air buoyancy corrections.

\subsection{Apparatus/Equipment Required}

2.3.1. Precision analytical balance or mass comparator with sufficient capacity and resolution for the planned calibrations.

2.3.2. Calibrated reference standards or working standards, of nominally equal mass to the unknown mass standards being calibrated. Calibrated tare weights are used as needed to ensure that the standard(s) and test artifacts are of equal nominal mass (See SOP 34 for suitable limits).

2.3.3. Calibrated sensitivity weights and tare weights selected to comply with the requirements of SOP 34.

2.3.4. Uncalibrated weights to be used to adjust the balance to the desired reading range if needed.

2.3.5. Forceps to handle the weights or gloves to be worn if the weights are moved by hand. Forceps and gloves must be selected to avoid damage or contamination to mass standards.

2.3.6. Stop watch or other timing device to observe the time of each measurement (calibration not required; this is used to ensure consistent timing of the 
measurement). If an electronic balance is used that has a means for indicating a stable reading, the operator may continue to time readings to ensure consistent timing that can minimize errors due to linear drift.

2.3.7. Calibrated barometer with sufficiently small resolution, stability, and uncertainty (See SOP 2, e.g., accurate to $\pm 66.5 \mathrm{~Pa}(0.5 \mathrm{~mm} \mathrm{Hg})$ ) to determine barometric pressure. ${ }^{4}$

2.3.8. Calibrated thermometer with sufficiently small resolution, stability, and uncertainty (see SOP 2, e.g., accurate to $\pm 0.10{ }^{\circ} \mathrm{C}$ ) to determine air temperature. ${ }^{4}$

2.3.9. Calibrated hygrometer with sufficiently small resolution, stability, and uncertainty (see SOP 2 , e.g., accurate to \pm 10 percent) to determine relative humidity. ${ }^{4}$

\subsection{Symbols}

Table 2. Symbols used in this procedure.

\begin{tabular}{|c|c|}
\hline Symbol & Description \\
\hline$S$ & standard reference weight \\
\hline$X$ & weight to be calibrated \\
\hline$S_{c}$ & check standard \\
\hline$t$ & $\begin{array}{l}\text { small calibrated tare weight, A subscript } s \text { or } x \text { is used to indicate the larger } \\
\text { weight with which it is associated }\end{array}$ \\
\hline$s w$ & small calibrated weight used to evaluate the sensitivity of the balance \\
\hline$M$ & $\begin{array}{l}\text { the mass (true mass) of a specific weight. Subscripts } s, x, t, s w \text { are used to } \\
\text { identify the weight (equals Nominal plus Correction) }\end{array}$ \\
\hline$N$ & $\begin{array}{l}\text { the nominal value of a specific weight. Subscripts } s, x \text {, are used to identify the } \\
\text { weight. }\end{array}$ \\
\hline$C$ & $\begin{array}{l}\text { the correction for a specific weight. Subscripts } s, x \text {, are used to identify the } \\
\text { weight. }\end{array}$ \\
\hline$C M$ & $\begin{array}{l}\text { the conventional mass of a specific weight. Subscripts } s, x, t, s w \text { are used to } \\
\text { identify the weight. }\end{array}$ \\
\hline
\end{tabular}

\footnotetext{
${ }^{4}$ The barometer, thermometer, and hygrometer are used to determine the air density at the time of the measurement. The air density is used to make an air buoyancy correction. The limits specified are recommended for high precision calibration.
} 


\begin{tabular}{||c|l||}
\hline$\rho_{a}$ & density of air at time of calibration \\
\hline$\rho_{n}$ & density of normal air $\left(1.2 \mathrm{~kg} / \mathrm{m}^{3}\right)$ \\
\hline$\rho$ & density of masses; subscripts $s, x, t_{s}, t_{x}, s w$ are used to identify the weight. \\
\hline
\end{tabular}

2.5. Procedure

\subsubsection{Preliminary Procedure}

2.5.1.1. Weights are visually inspected for cleanliness and damage. Follow the laboratory policy and customer contract review process to determine if and when standards will be cleaned, or where standards with inadequate cleanliness are returned without calibration, and when "as found" and "as left" values will be obtained through duplicate calibrations.

2.5.1.2. If cleaning weights, it is important to clean weights before any measurements are made, unless "as found' data is to be measured, because the cleaning process may change the mass of the weight. Cleaning should not remove any significant amounts of weight material. Weights should be handled and stored in such a way that they stay clean. Before calibration, dust and any foreign particles shall be removed by blowing air across the surface or by brushing with a clean soft bristled brush. Care must be taken not to change the surface properties of the weight (i.e., by scratching the weight). If a weight contains significant amounts of dirt that cannot be removed by the methods cited above, the weight or some part of it can be washed with clean alcohol, distilled water or other solvents. Weights with internal cavities should normally not be immersed in the solvent to avoid the possibility that the fluid will penetrate the opening. If there is a need to monitor the stability of a weight in use, the mass of the weight should, if possible, be determined before cleaning.

2.5.1.3.If weights are cleaned with solvents they must be stabilized for the times given in the following table:

Table 3. Cleaning Stabilization.

\begin{tabular}{|c|c|c|c|c||}
\hline Weight class & $\mathbf{E}_{\mathbf{1}}$ & $\mathbf{E}_{\mathbf{2}}$ & $\mathbf{F}_{\mathbf{1}}$ & $\mathbf{F}_{\mathbf{2}}$ to $\mathbf{M}_{\mathbf{3}}$ \\
\hline After cleaning with alcohol & 7 to 10 days & 3 to 6 days & 1 to 2 days & 1 hour \\
\hline After cleaning with distilled water & 4 to 6 days & 2 to 3 days & 1 day & 1 hour \\
\hline
\end{tabular}


2.5.1.4.Prior to performing any calibration tests, the weights need to be equilibrated to the ambient conditions of the laboratory. In particular, weights of classes $F_{1}$ (or better) should be close to the temperature in the weighing area. The minimum times (in hours) required for temperature stabilization (depending on weight size, weight class and on the difference between the initial temperature of the weights and the room temperature in the laboratory) are shown in the table below (with appropriate documented evidence). As a practical guideline, a waiting time of 24 hours is recommended. If weights are extremely hot or cold, additional equilibration is required to address problems with varying surface moisture. Weights must be completely dry prior to calibration.

Table 4. Minimum Equilibration Times ${ }^{5}$.

\begin{tabular}{|c|c|c|c|c|c|}
\hline$\overline{\Delta \Delta \mathrm{T}^{*}}$ & Nominal Mass ${ }^{6}$ & $\begin{array}{c}\text { OIML Class E }_{1} \\
\text { (time in } h)\end{array}$ & $\begin{array}{c}{\text { OIML Class } E_{2}}_{(\text {time in } h)}\end{array}$ & $\begin{array}{c}\text { OIML Class } \mathrm{F}_{1} \\
\text { (time in } \mathrm{h})\end{array}$ & $\begin{array}{c}\text { OIML Class } F_{2} \\
\text { to } M_{3} \\
\text { (time in } h \text { ) }\end{array}$ \\
\hline \multirow{7}{*}{ $\pm 20^{\circ} \mathrm{C}$} & $1000,2000,5000 \mathrm{~kg}$ & - & - & 79 & \begin{tabular}{|l|}
5 \\
\end{tabular} \\
\hline & $100,200,500 \mathrm{~kg}$ & - & 70 & 33 & 4 \\
\hline & $10,20,50 \mathrm{~kg}$ & 45 & 27 & 12 & 3 \\
\hline & $1,2,5 \mathrm{~kg}$ & 18 & 12 & 6 & 2 \\
\hline & $100,200,500 \mathrm{~g}$ & 8 & 5 & 3 & 1 \\
\hline & $10,20,50 \mathrm{~g}$ & 2 & 2 & 1 & 1 \\
\hline & $<10 \mathrm{~g}$ & 1 & 1 & 1 & 0.5 \\
\hline \multirow{7}{*}{ $\pm 5^{\circ} \mathrm{C}$} & $1000,2000,5000 \mathrm{~kg}$ & - & - & 1 & 1 \\
\hline & $100,200,500 \mathrm{~kg}$ & - & 40 & 4 & 1 \\
\hline & $10,20,50 \mathrm{~kg}$ & 36 & 18 & 4 & 1 \\
\hline & $1,2,5 \mathrm{~kg}$ & 15 & 8 & 3 & 1 \\
\hline & $100,200,500 \mathrm{~g}$ & 6 & 4 & 2 & 0.5 \\
\hline & $10,20,50 \mathrm{~g}$ & 2 & 1 & 1 & 0.5 \\
\hline & $<10 \mathrm{~g}$ & 0.5 & 0.5 & 0.5 & 0.5 \\
\hline \multirow{5}{*}{ $\pm 2{ }^{\circ} \mathrm{C}$} & $100 \mathrm{~kg}$ to $5000 \mathrm{~kg}$ & - & 16 & 1 & 0.5 \\
\hline & $10,20,50 \mathrm{~kg}$ & 27 & 10 & 1 & 0.5 \\
\hline & $1,2,5 \mathrm{~kg}$ & 12 & 5 & 1 & 0.5 \\
\hline & $100,200,500 \mathrm{~g}$ & 5 & 3 & 1 & 0.5 \\
\hline & $<100 \mathrm{~g}$ & 2 & 1 & 1 & 0.5 \\
\hline \multirow{5}{*}{ $\pm 0.5^{\circ} \mathrm{C}$} & $100 \mathrm{~kg}$ to $5000 \mathrm{~kg}$ & - & 1 & 0.5 & 0.5 \\
\hline & $10,20,50 \mathrm{~kg}$ & 11 & 1 & 0.5 & 0.5 \\
\hline & $1,2,5, \mathrm{~kg}$ & 7 & 1 & 0.5 & 0.5 \\
\hline & $100,200,500 \mathrm{~g}$ & 3 & 1 & 0.5 & 0.5 \\
\hline & $<100 \mathrm{~g}$ & 1 & 0.5 & 0.5 & 0.5 \\
\hline
\end{tabular}

$* \Delta \mathrm{T}=$ Initial difference between weight temperature and laboratory temperature.

${ }^{5}$ Consider equivalent ASTM Classes for equilibration times.

${ }^{6}$ Nominal masses in the 1, 2, 5 combinations include intermediate values such as 3 . 


\subsubsection{Weighing Design Matrix}

The following table shows the intercomparisons to be made in the 3-1 design, in a matrix format as shown in NBS Technical Note 952, Designs for the Calibration of Standards of Mass, J. M. Cameron, M. C. Croarkin, and R. C. Raybold, 1977:

Table 5. Weighing Design Matrix.

\begin{tabular}{||c|c|c|c||}
\hline $\begin{array}{c}\text { Weight ID } \\
\text { Comparison }\end{array}$ & $\mathrm{S}$ & $\mathrm{X}$ & $\mathrm{S}_{\mathrm{c}}$ \\
\hline \hline $\mathrm{a}_{1}$ & + & - & \\
\hline $\mathrm{a}_{2}$ & + & & - \\
\hline $\mathrm{a}_{3}$ & & + & - \\
\hline Standard & + & & + \\
\hline Check Standard & & & + \\
\hline
\end{tabular}

This design is represented as design ID "A.1.1"in Technical Note 952, with the exception that the design order is reversed and Restraint B is used ${ }^{7}$. The restraint is another name for the "standard" used in the comparison that may be found in NBS Technical Note 952. This matrix may be useful for data reduction purposes. When creating a data file for this design, the design matrix will appear as the numbers in the following table:

$\begin{array}{rccc}\text { Restraint } & 1 & 0 & 0 \\ \text { Check } & 0 & 0 & 1 \\ \text { Following series sum } & 0 & 0 & 0 \\ \text { Report } & 0 & 1 & 1 \\ \text { 1st double sub } & 1 & -1 & 0 \\ \text { 2nd double sub } & 1 & 0 & -1 \\ \text { 3rd double sub } & 0 & 1 & -1\end{array}$

\subsubsection{Measurement Procedure}

Record the pertinent information for the standard, S, unknown, X, and check standard, $\mathrm{S}_{\mathrm{c}}$, as indicated on a suitable data sheet such as the one in the Appendix of this SOP. Record the laboratory ambient temperature,

\footnotetext{
${ }^{7}$ Additional 3-1 weighing designs are published. This procedure provides the calculations and solutions only for this particular design positions of mass artifacts.
} 
barometric pressure, and relative humidity, before and after each measurement. If performing buoyancy corrections on each measurement, record environmental data before observations $1,5,9$ and after measurement 12. Perform the measurements in the order shown in the following table.

Table 6. Measurement Procedure.

\begin{tabular}{|c|c|c|c||}
\hline $\begin{array}{c}\text { Double } \\
\text { Substitution }\end{array}$ & $\begin{array}{c}\text { Measurement } \\
\text { Number }\end{array}$ & $\begin{array}{c}\text { Weights } \\
\text { on Pan }\end{array}$ & Observation \\
\hline \hline $\mathrm{a}_{1}: S$ vs $X$ & 1 & $S+t_{s}$ & $O_{1}$ \\
\hline & 2 & $X+t_{x}$ & $O_{2}$ \\
\hline & 3 & $X+t_{x}+s w$ & $O_{3}$ \\
\hline \hline $\mathrm{a}_{2}: S$ vs $S_{c}$ & 4 & $S+t_{s}+s w$ & $O_{4}$ \\
\hline & 6 & $S+t_{s}$ & $O_{1}$ \\
\hline & 7 & $S_{c}+t_{s c}$ & $O_{2}$ \\
\hline & 8 & $S_{c}+t_{s c}+s w$ & $O_{3}$ \\
\hline \hline $\mathrm{a}_{3}: X$ vs $S_{c}$ & 9 & $X+t_{s}+s w$ & $O_{4}$ \\
\hline & 10 & $S_{c}+t_{s c}$ & $O_{1}$ \\
\hline & 11 & $S_{c}+t_{s c}+s w$ & $O_{2}$ \\
\hline & 12 & $X+t_{x}+s w$ & $O_{3}$ \\
\hline
\end{tabular}

3. Calculations

3.1. Calculate the average air density, $\rho_{A}$, as described in the Appendix to NISTIR 6969, SOP No. 2, Option B.

3.2. Calculate the measured differences, $\mathrm{a}_{1}, \mathrm{a}_{2}$, and $\mathrm{a}_{3}$, for the weights used in each double substitution using the following formula (note: do not confuse this formula with the calculations used in SOP 4, NISTIR 6969; the signs will be opposite SOP 4, Option A.):

$$
a_{x}=\frac{\left(O_{1}-O_{2}+O_{4}-O_{3}\right)}{2} \frac{M_{s w}\left(1-\frac{\rho_{A}}{\rho_{s w}}\right)}{O_{3}-O_{2}}
$$

3.3. Calculate the within process standard deviation, $\mathrm{s}_{\mathrm{w}}$, for the 3-1 weighing design. This 
standard deviation has one degree of freedom.

$s_{w}=0.577\left(a_{1}-a_{2}+a_{3}\right)$

3.4. Calculate the F statistic which compares the within process standard deviation, $\mathrm{s}_{\mathrm{w}}$, to the pooled within process standard deviation (or accepted within process standard deviation). (See chapter 8.4 and 8.5 in NISTIR 6969, for a discussion of the statistics used in weighing designs.)

$$
F-\text { statistic }=\frac{s_{w}{ }^{2}}{\left(\text { Pooled }_{S_{w}}\right)^{2}}
$$

The F-statistic so computed must be less than the F-value obtained from an F-table at $99 \%$ confidence level (Table 9.5, NISTIR 6969) to be acceptable. The F-value is obtained from the F-table for numerator degrees of freedom equal one, and denominator degrees of freedom equal to the number of degrees of freedom in the pooled within process standard deviation. If the data fails the F-test and the source of the error cannot be determined conclusively, the measurement must be repeated.

3.5. Calculate the observed mass value of the check standard.

Calculate the least-squares measured difference $d_{s c}$ for $S_{c}$.

$$
d_{s_{c}}=\frac{-a_{1}-2 a_{2}-a_{3}}{3}
$$

3.6. Calculate the observed mass of $\mathrm{S}_{\mathrm{c}}, \mathrm{M}_{\mathrm{sc}}$.

$$
M_{s c}=\frac{M_{s}\left(1-\frac{\rho_{A}}{\rho_{s}}\right)+d_{s c}+M_{t_{s}}\left(1-\frac{\rho_{A}}{\rho_{t_{s}}}\right)-M_{t_{s c}}\left(1-\frac{\rho_{A}}{\rho_{t_{s c}}}\right)}{\left(1-\frac{\rho_{A}}{\rho_{s c}}\right)}
$$

3.6.1. Calculate the Conventional Mass of $\mathrm{S}_{\mathrm{c}}, \mathrm{CM}_{\mathrm{Sc}}$ :

$$
C M_{S c}=\frac{M_{S c}\left(1-\frac{0.0012}{\rho_{S c}}\right)}{0.999850}
$$

3.7. Evaluate the mass $\mathrm{M}_{\mathrm{sc}}$, or conventional mass $\mathrm{CM}_{\mathrm{sc}}$, of $\mathrm{S}_{\mathrm{c}}$. 
The mass or conventional mass is evaluated with a t-test in the procedure based on comparison with the accepted mass or conventional mass value. The mass or conventional mass (depending on what is tracked in the laboratory) is also plotted on the control chart and must lie within the control limits (See NISTIR 6969, SOP 9). If the value is not within limits, and the source of error cannot be found, measurement must be stopped until suitable corrective action is taken. Corrective action is demonstrated through evaluation of additional measurement results that are within limits.

Calculate $E_{n}$ to compare the mean mass value of the check standard, $M_{s c}$ from the 3-1 design to the accepted and calibrated reference value $\left(R_{S c}\right)$ that has adequate metrological traceability for the check standard.

$$
E_{n}=\frac{\left|\bar{M}_{S c}-R_{S c}\right|}{\sqrt{U_{M_{s c}}^{2}+U_{R_{S c}}^{2}}}
$$

The $E_{n}$ value must be less than one to pass.

3.8. Calculate the least-squares measured difference, $d_{x}$, for $X$.

$$
d_{x}=\frac{-2 a_{1}-a_{2}+a_{3}}{3}
$$

3.9. Calculate the mass of $\mathrm{X}, \mathrm{M}_{\mathrm{X}}$.

$$
M_{x}=\frac{M_{s}\left(1-\frac{\rho_{A}}{\rho_{s}}\right)+d_{x}+M_{t_{s}}\left(1-\frac{\rho_{A}}{\rho_{t_{s}}}\right)-M_{t_{x}}\left(1-\frac{\rho_{A}}{\rho_{t_{x}}}\right)}{\left(1-\frac{\rho_{A}}{\rho_{x}}\right)}
$$

3.10. Calculate the conventional mass ${ }^{8}$ of $X, C M_{x}$. The conventional mass should be reported.

\subsubsection{Conventional mass}

\footnotetext{
${ }^{8}$ Conventional Mass: "The conventional value of the result of weighing a body in air is equal to the mass of a standard, of conventionally chosen density, at a conventionally chosen temperature, which balances this body at this reference temperature in air of conventionally chosen density." The conventions are: artifact reference density 8.0 $\mathrm{g} / \mathrm{cm}^{3}$; reference temperature $20^{\circ} \mathrm{C}$; normal air density $0.0012 \mathrm{~g} / \mathrm{cm} 3$. Conventional mass was formerly called "Apparent Mass versus $8.0 \mathrm{~g} / \mathrm{cm}^{3 "}$ " in the United States. See OIML D28 (2004).
} 


$$
C M_{x}=\frac{M_{x}\left(1-\frac{0.0012}{\rho_{x}}\right)}{0.999850}
$$

3.10.2. If requested, the apparent mass versus the reference density of brass may be calculated. This value should only be provided when requested by the customer for use when calibrating mechanical balances that have been adjusted to this reference density. (This is rare.) Apparent mass versus brass $\left(8.3909 \mathrm{~g} / \mathrm{cm}^{3}\right.$ at $\left.20^{\circ} \mathrm{C}\right)$

$$
A M_{x} \text { vs. } 8.4=\frac{M_{x}\left(1-\frac{0.0012}{\rho_{x}}\right)}{\left(1-\frac{0.0012}{8.3909}\right)}
$$

4. Measurement Assurance

4.1. The process integrates a suitable check standard (See GLP 1, SOP 9, SOP 30, and Sec. 7.4).

4.2. The check standard value is calculated and immediately evaluated to verify that the mass is within established limits; a t-test may be incorporated to check observed value against accepted value.

4.3. The mean value of the check standard is compared to a reference value of the check standard with respect to their applicable expanded uncertainties to evaluate bias and drift over time. The mean value over time may be used to monitor drift in the standard or check standard. Excessive drift or bias must be investigated and followed with suitable corrective action.

4.4. Check standard observations obtained over time are used to calculate the standard deviation of the measurement process, $s_{p}$.

\section{Assignment of Uncertainty}

The limits of expanded uncertainty, $U$, include estimates of the standard uncertainty of the mass standards used, $u_{s}$, estimates of the standard deviation of the measurement process, $s_{p}$, and estimates of the effect of other components associated with this procedure, $u_{o}$. These estimates should be combined using the root-sum-squared method (RSS), and the expanded uncertainty, $U$, reported with a coverage factor to be determined based on the degrees of freedom, which if large enough will be 2, $(k=2)$, to give an approximate 95 percent level of confidence. See SOP 29, "Standard Operating Procedures for the Assignment of Uncertainty" (NISTIR 6969), for the complete standard operating 
procedure for calculating the uncertainty.

When the 3-1 weighing design is used in conjunction with specialized software for data reduction, see SOP 28, "Recommended Standard Operating Procedure for Using Advanced Weighing Designs", for detailed instructions on calculating the uncertainty components which are required.

5.1. The expanded uncertainty for the standard, $U$, is obtained from the calibration certificate. The combined standard uncertainty, $u_{c}$, is used and not the expanded uncertainty, $U$, therefore the reported uncertainty for the standard will usually need to be divided by the coverage factor $k$. When multiple standards are used, see SOP 29 for evaluation of dependent and independent conditions and combining methods for the standard uncertainty of the standard. Usually only one standard is used as the restraint for the 3-1 weighing design, the uncertainty of the check standard is not included in assigning an uncertainty to the unknown mass.

5.2. The value for the standard deviation of the measurement process $\mathrm{s}_{\mathrm{p}}$ is obtained from the control chart data for check standards using only 3-1 weighing design measurements (see SOP No. 9.) The within-process standard deviation, $s_{\mathrm{w}}$, is only used as a part of the process variability evaluation using the F-test unless between time components are also determined. In that case, the standard deviation of the process, $\mathrm{s}_{\mathrm{p}}$, is treated as $\mathrm{s}_{\mathrm{t}}$ (standard deviation over time) and see NISTIR 5672, SOP 28 for details. Statistical control must be verified by the measurement of the check standard in the 3-1 design.

5.2.1. Where the standard deviation of the measurement process is less than the resolution of the balance being used, the larger of the $s_{p}$ and the result from equation in SOP 29 should be used.

5.2.2. For SOP 5 and a digital balance with the scale interval, $d$, the smallest standard uncertainty due to resolution of the balance used in the measurement process may use:

$$
u_{d}=\frac{d / 2}{\sqrt{3}}
$$

Because SOP 5 uses an average of the observations from redundant weighing designs, a smaller value may be used when the standard deviation of the process is less than the balance resolution. The larger of the standard deviation of the measurement process over time or this value is to be used.

5.3. Uncertainty due to air buoyancy corrections and air density. Select one of the following options in priority preference for calculating and uncertainty associated with air buoyancy. 
5.3.1. Option 1. Use the formulae provided in OIML R111, C.6.3-1, C.6.3-2, and C.6.3-3.

5.3.2. Option 2. Calculate the uncertainty by quantify estimated impacts associated with the uncertainties of the air temperature, barometric pressure, relative humidity, and the air density formula based on laboratory uncertainties and calculations given in NISTIR 6969, SOP 2 and the SOP being used. Note: this may be done using a simplified "baseline approach" or a Kragten analysis. Note: this may be done using a simplified "baseline approach" or a Kragten analysis."

5.3.3. Option 3. In the event that buoyancy corrections are not performed, include an uncorrected systematic standard uncertainty due to the buoyancy effect using the equations for the magnitude of the air buoyancy correction per SOP 2 and use a rectangular distribution. This approach is not recommended for precision calibrations; however, if the resulting value from this approach does not significantly affect the expanded uncertainty, it may be adequate.

5.4. Uncertainty associated with the density of the standards and the unknown test weights, $u_{\rho}$. Uncertainties associated with the density of the standards used in the calibration may be incorporated into the estimated calculations in section 5.3.

5.5. Uncertainty associated with bias, $u_{d}$. Any noted bias that has been determined through analysis of control charts and round robin data must be less than limits provided in SOP 29 and should be included if corrective action is not taken. See SOP 2 and 29 for additional details.

5.6. Example components to be considered for an uncertainty budget table are shown in the following table.

Table 6. Example uncertainty budget table.

\begin{tabular}{|c|c|c|c|}
\hline $\begin{array}{l}\text { Uncertainty Component } \\
\text { Description }\end{array}$ & Symbol & Source & $\begin{array}{c}\text { Typical } \\
\text { Distribution }\end{array}$ \\
\hline $\begin{array}{l}\text { Uncertainty of the standard } \\
\text { mass(es) }(5.1)\end{array}$ & $u_{s}$ & Calibration certificate & $\begin{array}{c}\text { Rectangular or } \\
\text { Normal divided } \\
\text { by coverage factor }\end{array}$ \\
\hline $\begin{array}{l}\text { Accepted standard deviation of } \\
\text { the process (5.2) }\end{array}$ & $s_{p}$ & $\begin{array}{c}\text { Control chart, standard deviation } \\
\text { chart }\end{array}$ & Normal \\
\hline $\begin{array}{l}\text { Uncertainty of the buoyancy } \\
\text { correction }(5.3)\end{array}$ & $u_{b}$ & OIML R111 & Rectangular \\
\hline
\end{tabular}

${ }^{9}$ A "baseline approach" calculates the estimated impact of each variable in the final measurement result by individually changing each variable of interest by the uncertainty quantity. See the EURACHEM/CITAC Quantitative Guide to Uncertainties in Analytical Methods (QUAM, 2012) for a discussion of Kragten spreadsheets. 


\begin{tabular}{||l|c|c|c||}
\hline \multicolumn{1}{|c|}{$\begin{array}{c}\text { Uncertainty Component } \\
\text { Description }\end{array}$} & Symbol & Source & $\begin{array}{c}\text { Typical } \\
\text { Distribution }\end{array}$ \\
\hline Air temperature (for air density) & $u_{t}$ & SOP 2 or OIML R111 & Rectangular \\
\hline Air pressure (for air density) & $u_{p}$ & SOP 2 or OIML R111 & Rectangular \\
\hline $\begin{array}{l}\text { Air relative humidity (for air } \\
\text { density) }\end{array}$ & $u_{R H}$ & SOP 2 or OIML R111 & Rectangular \\
\hline Air density (formula) & $u_{\rho a}$ & SOP 2 or OIML R111 & Rectangular \\
\hline Mass densities (5.4) & $u_{\rho m}$ & $\begin{array}{c}\text { Measured and reported value } \\
\text { OIML R111 Table B.7 } \\
\text { Typically 0.03 g/cm }{ }^{3} \text { to 0.05 g/cm }\end{array}$ & Rectangular \\
\hline $\begin{array}{l}\text { Uncertainty associated with bias } \\
(5.5)\end{array}$ & $u_{d}$ & Control chart, proficiency tests & See SOP 29 \\
\hline \hline
\end{tabular}

5.7. Evaluate compliance to applicable tolerances as needed by the customer. The expanded uncertainty, $U$, must be $\leq 1 / 3$ of the applicable tolerances published in ASTM E 617 and OIML R111 standards. Additionally, the mass value plus the expanded uncertainty must be less than the applicable tolerance to confidently state that mass standards are in or out of tolerance.

5.8. Draft a suitable uncertainty statement for the certificate (e.g.,)

The uncertainty reported is the root sum square of the standard uncertainty of the standard, the standard deviation of the process, and an uncorrected systematic error for lack of buoyancy corrections, multiplied by a coverage factor of $2(k=2)$ for an approximate 95 percent confidence interval. Factors not considered in the evaluation: magnetism (weights are considered to meet magnetism specifications unless measurement aberrations are noted), balance eccentricity and linearity (these factors are considered as a part of the measurement process when obtaining the standard deviation of the process when using a check standard with adequate degrees of freedom.

\section{Certificate}

Report results as described in SOP No. 1, Preparation of Calibration Certificates. 


\section{Appendix \\ 3-1 Weighing Design When Tare Weights Are Used}

Laboratory data and conditions:

\begin{tabular}{|r|r|r|r||}
\hline Operator & Before & After \\
\hline Date & Temperature ${ }^{\circ} \mathrm{C}$ & & \\
\hline Balance & Boad & Relative Humidity $\%$ & \\
\hline Pooled within process s.d., $\mathrm{s}_{\mathrm{w}}=$ & & Degrees of freedom for process s.d. & \\
\hline Check standard s.d., $\mathrm{s}_{\mathrm{p}}=$ & & Degrees of freedom from control chart & \\
\hline
\end{tabular}

\section{Mass standard(s) data:}

\begin{tabular}{|c|c|c|c|c|c|}
\hline ID (Insert Set or SN) & Nominal & Mass Correction & $\begin{array}{l}\text { Expanded Unc: } \\
\text { from cal. certificate }\end{array}$ & $\begin{array}{l}\text { Unc: } \\
\text { k factor }\end{array}$ & $\begin{array}{l}\text { Density } \\
\mathrm{g} / \mathrm{cm}^{3}\end{array}$ \\
\hline $\mathrm{S}$ & & & & & \\
\hline$t_{s}$ & & & & & \\
\hline$X$ & & & & & \\
\hline$t_{x}$ & & & & & \\
\hline$S_{c}$ & & & & & \\
\hline$t_{S c}$ & & & & & \\
\hline$s w$ & & & & & \\
\hline
\end{tabular}

Laboratory observations:

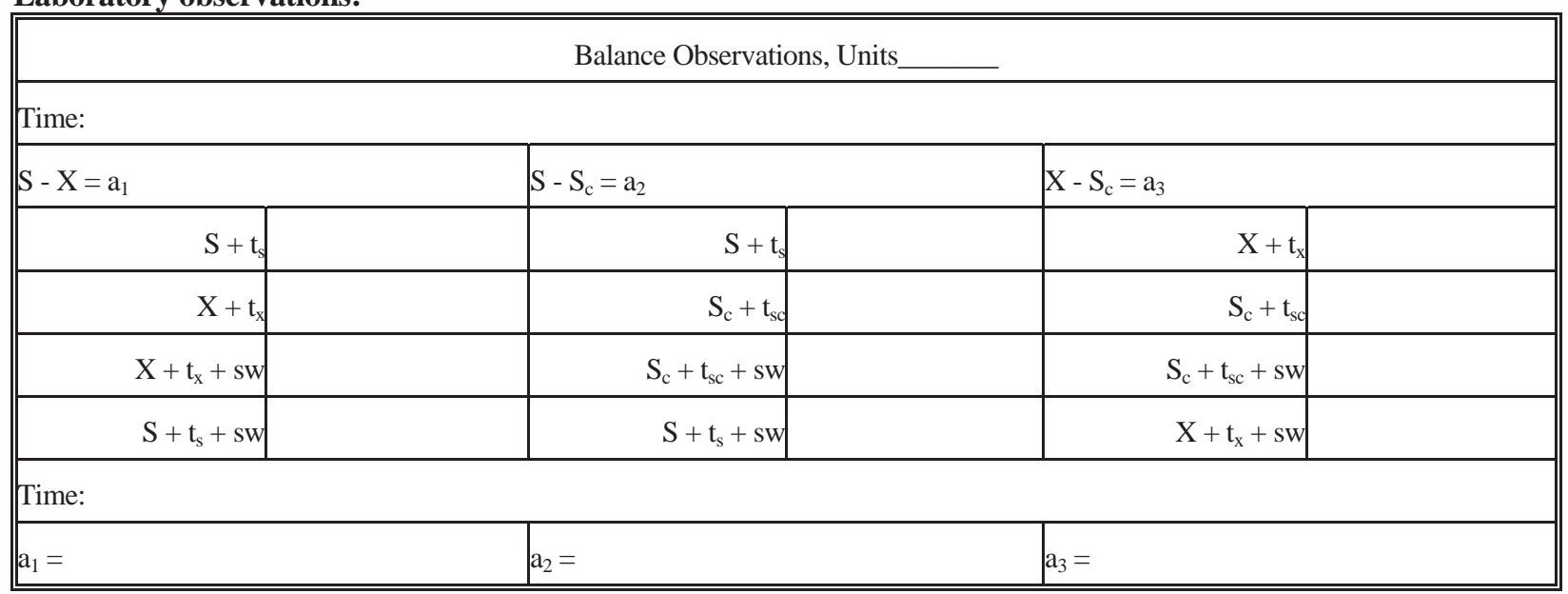




\section{Appendix A - Flow Chart of the 3-1 Weighing Design Process}

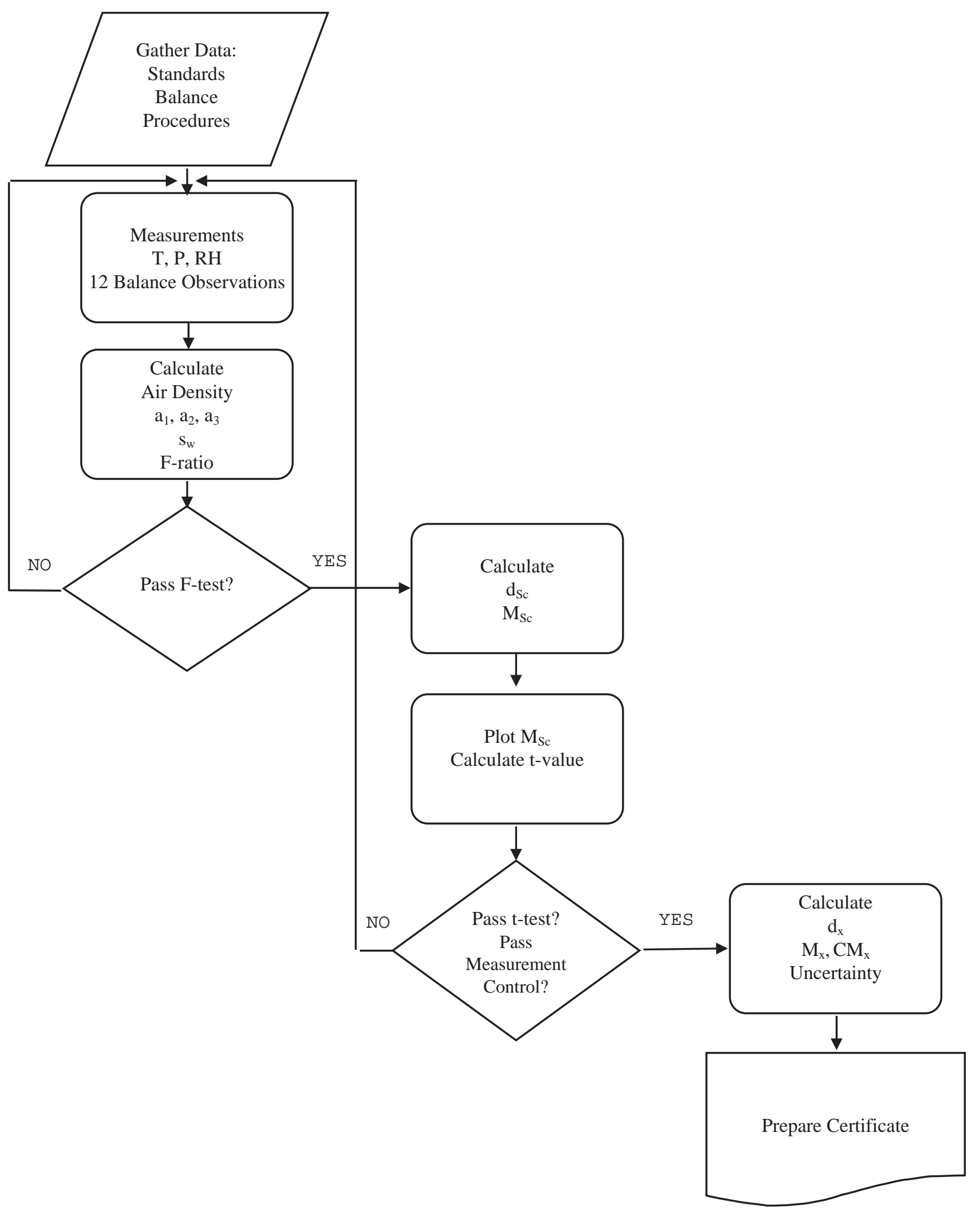


SOP No. 28

\section{Recommended Standard Operating Procedure for Using Advanced Weighing Designs}

1. Introduction

\subsection{Purpose}

Advanced weighing designs use a combination of double substitution comparisons of weights of equal nominal value or a series of weights in ascending or descending order; standard(s), unknown weights, and an additional standard called a check standard. The weights are intercompared using an equal-arm, single-pan mechanical, full electronic, or a combination balance utilizing built-in weights and a digital indication. The specific SOP for the double substitution procedure for each balance is to be followed. Weighing designs provide two methods of checking the validity of the measurement using an F-test to check the measurement process and a t-test to evaluate the stability of the standard and check standard. Hence, the procedure is especially useful for high accuracy calibrations in which it is critical to assure that the measurements are valid and well documented. This procedure is recommended for precision calibration of laboratory working standards that are subsequently used for lower level calibrations, for routine calibration of precision mass standards used for calibration of other mass standards, and for surveillance of mass reference and working standards.

\subsection{Prerequisites}

1.2.1. Calibrated mass standards, with recent calibration values and which have demonstrated metrological traceability to the international system of units (SI), which may be to the SI through a National Metrology Institute such as NIST.

1.2.2. Standards must be evaluated to ensure that standard uncertainties for the intended level of calibration are sufficiently small. Reference standards should only be used to calibrate the next lower level of working standards in the laboratory and should not be used to routinely calibrate customer standards.

1.2.3. Verify that the balance used is in good operating condition with sufficiently small process standard deviation as verified by F-test values, pooled short term standard deviations, and by a valid control chart for check standards, or preliminary experiments to ascertain its performance 
quality when new balances are put into service. See NISTIR $5672^{1}$ for a discussion on the performance levels expected for use of these procedures as part of a laboratory measurement assurance program to ensure traceability of laboratory standards.

1.2.4. Verify that the operator is experienced in precision weighing techniques, and has had specific training in SOP 2, SOP 4, SOP 5, SOP 29, and is familiar with the concepts in GMP 10. Further, the operator must have been trained in the creation of data files and the operation of the NIST Mass Code when it is used for data reduction as recommended. Example data sets and sample observation sheets are available in the Advanced Mass Seminar offered by the NIST Office of Weights and Measures.

1.2.5. Laboratory facilities must comply with the following minimum conditions to meet the expected uncertainty possible with this procedure and to comply with the balance manufacturer's operating conditions specified for the balance. Equilibration of balances and weights requires environmental stability of the laboratory within the stated limits for a minimum of 24 hours before a calibration.

Table 1. Environmental conditions.

\begin{tabular}{|c|c|c|}
\hline Echelon $^{2}$ & Temperature Requirements During a Calibration & $\begin{array}{l}\text { Relative Humidity } \\
(\%) \\
\end{array}$ \\
\hline \multirow{2}{*}{ I } & $\begin{array}{c}\text { OIML } \mathrm{E}_{1}, \text { ASTM 000, 00, } 0 \\
\text { Lower and upper limits: } 18^{\circ} \mathrm{C} \text { to } 23^{\circ} \mathrm{C} \\
\text { Maximum changes: } \pm 0.5^{\circ} \mathrm{C} / 12 \mathrm{~h} \text { and } \pm 0.3^{\circ} \mathrm{C} / \mathrm{h}\end{array}$ & \multirow{2}{*}{40 to $60 \pm 5 / 4 h$} \\
\hline & $\begin{array}{c}\text { OIML E } \mathrm{E}_{2} \text {, ASTM } 1 \\
\text { Lower and upper limits: } 18^{\circ} \mathrm{C} \text { to } 23^{\circ} \mathrm{C} \\
\text { Maximum changes: } \pm 1^{\circ} \mathrm{C} / 12 \mathrm{~h} \text { and } \pm 0.7^{\circ} \mathrm{C} / \mathrm{h}\end{array}$ & \\
\hline
\end{tabular}

1.2.5.1. It is important that the difference in temperature between the weights and the air inside the mass comparator is as small as possible. Keeping the reference weight and the test weight inside, or next to, the mass comparator before and during the calibration can reduce this temperature difference. Standards and test artifacts must be allowed to reach equilibration in or near the balance before starting measurements.

\footnotetext{
${ }^{1}$ Fraley, K. L., Harris, Georgia G. L., NIST IR 5672, Advanced Mass Calibration and Measurement Assurance Program for State Calibration Laboratories, March 2012.

2 Echelon I corresponds to weights of Classes OIML $E_{1}$ and $E_{2}$, Echelon II corresponds to weights of Classes OIML $\mathrm{F}_{1}$ and $\mathrm{F}_{2}$. 
2. Methodology

\subsection{Scope, Precision, Accuracy}

This method can be performed on any type of balance using the appropriate double substitution SOP for the particular balance. Because considerable effort is involved, this weighing design is most useful for calibrations of the highest accuracy. The weighing design utilizes a combination of double substitutions to calibrate a single unknown weight, or a group of related weights in a decade. This method introduces redundancy into the measurement process and permits two checks on the validity of the measurement; one on accuracy and stability of the standard using an integrated t-test and the other on process repeatability using an F-test. A least-squares best fit analysis is done on the measurements to assign a value to the unknown weights. The standard deviation of the process depends upon the resolution of the balance and the care exercised to make the required weighings. The accuracy will depend upon the accuracy and uncertainty of the calibration of the restraint weights and the precision of the comparison.

2.2. Summary

A restraint weight, $S$, in some cases two restraint weights, $S_{1}$ and $S_{2}$, an unknown weight, $\mathrm{X}$, or group of unknown weights, and a check standard, Sc are compared in a specific order typically using the double substitution procedure although other procedures may be appropriate. The balance and the weights must be prepared according to the appropriate SOP for the particular balance being used. Once the balance and weights have been prepared, all readings must be taken from the reading scale of the balance without adjusting the balance or weights in any way. Within a double substitution all weighings are made at regularly spaced time intervals to minimize effects due to instrument drift. Because of the amount of effort required to perform weighing designs, the procedure includes an air buoyancy correction using the average air density as determined immediately before and after the weighings, drift-free equation for calculating the observed differences, correction for the cubical coefficient of expansion when measurements are not made at $20{ }^{\circ} \mathrm{C}$, an average sensitivity for the balance over the range of measurements made, and the international formula for air density.

\subsection{Apparatus/Equipment Required}

2.3.1. Precision analytical balance or mass comparator with sufficient capacity and resolution for the calibrations planned.

2.3.2. Calibrated reference standards (usually starting at $1 \mathrm{~kg}$ or $100 \mathrm{~g}$ ), calibrated check standards for each decade (e.g., 1 kg, 100 g, 10 g, 1 g,

\footnotetext{
${ }^{3}$ See SOP 2, published in NISTIR 6969, Selected Procedures for Mass Calibrations, 2012. The difference between Option A and Option B in SOP 2 is less than the uncertainty associated with assumptions made in the air density equations.
} 
$100 \mathrm{mg}, 10 \mathrm{mg}, 1 \mathrm{mg}$ for the seven series between $1 \mathrm{~kg}$ and $1 \mathrm{mg}$ ), and working standards.

2.3.3. Calibrated sensitivity weights and tare weights selected to comply with the requirements of SOP 34. Note: The calculations performed by the Mass Code do not take into consideration the value of any tare weights used in the weighing design. Additional calculations will be required when tare weights are used.

2.3.4. Uncalibrated weights to be used to adjust the balance to the desired reading range if needed.

2.3.5. Forceps to handle the weights, or gloves to be worn if the weights are moved by hand. Forceps and gloves must be selected to avoid damage or contamination of mass standards.

2.3.6. Stop watch or other timing device to observe the time of each measurement (calibration not required; this is used to ensure consistent timing of the measurement). If an electronic balance is used that has a means for indicating a stable reading, the operator may continue to time readings to ensure consistent timing that can minimize errors due to linear drift.

2.3.7. Calibrated barometer with sufficiently small resolution, stability, and uncertainty (See SOP 2, e.g., accurate to $\pm 66.5 \mathrm{~Pa}(0.5 \mathrm{~mm} \mathrm{Hg})$ ) to determine barometric pressure. ${ }^{4}$

2.3.8. Calibrated thermometer with sufficiently small resolution, stability, and uncertainty (see SOP 2, e.g., accurate to $\pm 0.10{ }^{\circ} \mathrm{C}$ ) to determine air temperature. $^{3}$

2.3.9. Calibrated hygrometer with sufficiently small resolution, stability, and uncertainty (see SOP 2, e.g., accurate to \pm 10 percent) to determine relative humidity. ${ }^{3}$

2.3.10. Computer with sufficient processing capability and memory.

\subsection{Procedure}

\subsubsection{Preliminary Procedure}

2.4.1.1. Weights are visually inspected for cleanliness and damage.

2.4.1.2. If cleaning weights, it is important to clean weights before any measurements are made because the cleaning process may change

\footnotetext{
4 The barometer, thermometer, and hygrometer are used to determine the air density at the time of the measurement. The air density is used to make an air buoyancy correction. The limits specified are recommended for high precision calibration. 
the mass of the weight. Cleaning should not remove any significant amounts of weight material. Weights should be handled and stored in such a way that they stay clean. Before calibration, dust and any foreign particles shall be removed. Care must be taken not to change the surface properties of the weight (i.e. by scratching the weight). If a weight contains significant amounts of dirt that cannot be removed by the methods cited above, the weight or some part of it can be washed with clean alcohol, distilled water or other solvents. Weights with internal cavities should normally not be immersed in the solvent to avoid the possibility that the fluid will penetrate the opening. If there is a need to monitor the stability of a weight in use, the mass of the weight should, if possible, be determined before cleaning.

2.4.1.3. If weights are cleaned with solvents they must be stabilized for at least 7 to 10 days.

2.4.2. Prior to making measurements, place the test weight and standards in the balance chamber or near the balance overnight to permit the weights and the balance to attain thermal equilibrium, or use a thermal soaking plate next to the balance with weights covered. Thermal equilibration time is particularly important with weights larger than 1 gram. An alternative heat source such as a heat lamp may further improve temperature stability in front of the balance. Conduct preliminary measurements to determine the size of the sensitivity weight and any tare weights that are required following SOP 34; adjust the balance to the appropriate reading range of the balance indications, and to exercise the balance. Refer to the appropriate double substitution SOP for details.

\subsubsection{Weighing Designs}

The table below shows the most common comparisons to be made as referenced in NBS Technical Note 952, Designs for the Calibration of Standards of Mass, J. M. Cameron, M. C. Croarkin, and R. C. Raybold, 1977. Each series is characterized by the number of observations, $n$, the degrees of freedom, d.f., associated with the standard deviation, the number of weights in each design, $\mathrm{k}$ (not shown in this table), the number of restraints (standards), and check standards, along with appropriate positions within the design*.

*Positions for check standards must be carefully considered as subsequent equations may be dependent on the position of use.

Table 2. Common weighing designs.

\begin{tabular}{|c|c|c|c|c|c||}
\hline $\begin{array}{c}\text { Design } \\
\text { ID }\end{array}$ & Description & $\begin{array}{c}\text { d.f. } \\
\text { Observations }\end{array}$ & $\begin{array}{c}\text { Degrees of } \\
\text { freedom }\end{array}$ & $\begin{array}{c}\text { Restraint } \\
\text { Position }\end{array}$ & $\begin{array}{c}\text { Check Std } \\
\text { Position* }\end{array}$ \\
\hline
\end{tabular}




\begin{tabular}{||c|l|c|c|c|c||}
\hline \hline $\begin{array}{c}\text { Design } \\
\text { ID }\end{array}$ & \multicolumn{1}{|c|}{ Description } & $\begin{array}{c}n \\
\text { Observations }\end{array}$ & $\begin{array}{c}\text { d.f. } \\
\text { Degrees of } \\
\text { freedom }\end{array}$ & $\begin{array}{c}\text { Restraint } \\
\text { Position }\end{array}$ & $\begin{array}{c}\text { Check Std } \\
\text { Position* }\end{array}$ \\
\hline \hline A.1.1 & 3-1 Weighing Design & 3 & 1 & 1 & 3 \\
\hline A.1.2 & $4-1$ Weighing Design & 6 & 3 & 1,2 & 3 or 4 \\
\hline A.1.4 & 5-1 Weighing Design & 10 & 6 & 1,2 & 3,4, or 5 \\
\hline A.2.1 & 6-1 Weighing Design & 8 & 3 & 1,2 & $3,4,5$, or 6 \\
\hline C.1** & 5, 3, 2, 1, 1 Design (descending) & 8 & 4 & $1,2,3$ & 5 or 4 \\
\hline C.1 & $5,3,2,1,1$ Design (ascending) & 8 & 4 & 5 & 4 \\
\hline C.2 & $5,3,2,1,1,1$ Design (descending) & 11 & 6 & $1,2,3$ & 4,5, or 6 \\
\hline C.2 & $5,3,2,1,1,1$ Design (ascending) & 11 & 6 & 6 & 4 or 5 \\
\hline C.9** & 5, 2, 2, 1, 1 Design (descending) & 8 & 4 & $1,2,3,4$ & 5 \\
\hline C.9 & $5,2,2,1,1$ Design (ascending) & 8 & 4 & 5 & 4 \\
\hline C.10 & 5, 2, 2, 1, 1, 1 Design (descending) & 8 & 3 & $1,2,3,4$ & 5 or 6 \\
\hline C.10 & $5,2,2,1,1,1$ Design (ascending) & 8 & 3 & 6 & 4 or 5 \\
\hline
\end{tabular}

**If these designs are NOT the last in a series, there is no position for a check standard.

The "restraint" is another name for the standard used in the comparison. Matrices are shown in Technical Note 952. Determine the best design prior to beginning the series. The series shown allow calibration of any commonly found set of mass standards in the 5, 2, 2, 1 combination or the $5,3,2,1$ combination.

\subsubsection{Measurement Procedure}

Record the pertinent information for all weights being intercompared on a suitable data sheet unless an automated data collection system is being used to collect the data and create a data file. Record or collect the laboratory ambient temperature, barometric pressure, and relative humidity immediately before and immediately after each series of intercomparisons.

\section{Calculations}

Calculations are completed by the NIST Mass Code as described in NBS Technical Note 1127, National Bureau of Standards Mass Calibration Computer Software, R. N. Varner, and R. C. Raybold, July 1980, with updates to conform to the international formula for calculating air density and the ISO/IEC Guide to the Expression of Uncertainties as described in the NIST Technical Note 1297 and minor error corrections to the original

\footnotetext{
${ }^{5}$ Design a.1.1. with inverted order (y3, y2, and y1), with restraint in position 1 (B) is detailed in SOP 5.
} 
code. The Mass Code performs two statistical tests (t-test and F-test) to verify both the value of the restraints and check standards, and to verify that the measurement process was in control during the comparisons.

3.1. Calculating Effective Densities and Coefficients of Expansion for Summations :

Some designs use a summation mass and sometimes the individual masses of this summation will be constructed from different materials that have different densities and coefficients of expansion. The following equations will be used to calculate the effective density and effective coefficient of expansions for the summation that will be needed as input for the data file. The subscripts 5, 3, and 2 refer to the individual masses that comprise the summation. This approach may also be needed with a 5, 2, 2, 1 combination.

$$
\text { Effective Density }=\frac{M_{5}+M_{3}+M_{2}}{\left(\frac{M_{5}}{\rho_{5}}\right)+\left(\frac{M_{3}}{\rho_{3}}\right)+\left(\frac{M_{2}}{\rho_{2}}\right)}
$$

Effective Cubical Coefficient of Expansion $=\frac{\left(\frac{M_{5}}{\rho_{5}} \alpha_{5}\right)+\left(\frac{M_{3}}{\rho_{3}} \alpha_{3}\right)+\left(\frac{M_{2}}{\rho_{2}} \alpha_{2}\right)}{\left(\frac{M_{5}}{\rho_{5}}\right)+\left(\frac{M_{3}}{\rho_{3}}\right)+\left(\frac{M_{2}}{\rho_{2}}\right)}$

Table 3. Variables for equations above.

\begin{tabular}{|c|l||}
\hline \hline Variable & \multicolumn{1}{c|}{ Description } \\
\hline \hline$M$ & Mass $(\mathrm{g})$ \\
\hline$\rho$ & Density $\left(\mathrm{g} / \mathrm{cm}^{3}\right)$ \\
\hline$\alpha$ & Cubical Coefficient of Expansion $\left(/{ }^{\circ} \mathrm{C}\right)$ \\
\hline
\end{tabular}

4. Assignment of Uncertainty

The NIST Mass Code generates uncertainties as a part of the data reduction. Proper input in the data file is critical for obtaining valid results and is dependent upon a well characterized measurement process. See NISTIR 5672 for a discussion on the input for standard uncertainties in the data file.

4.1. Calculating the standard uncertainty, $\mathrm{u}_{\mathrm{S}}$, of the starting restraint in the first series:

Usually the starting restraint will be one or several $1 \mathrm{~kg}$ (or $100 \mathrm{~g}$ ) mass standards that have calibrations and density determinations from a National Metrology

6Jaeger, K B., and R. S. Davis, NIST Special Publication 700-1, A Primer for Mass Metrology, November 1984. 
Institute or an accredited laboratory. The uncertainty of the standard as stated on a calibration report is divided by the appropriate coverage factor, dependent on the confidence interval stated in the calibration certificate.

One starting restraint scheme (a single starting standard), where $U_{S}$ is the uncertainty from NIST which must be divided by the proper coverage factor, $\mathrm{k}$.

$$
u_{s}=\frac{U_{s}}{k_{\text {factor }}}
$$

Multiple starting restraint schemes with standards calibrated at the same time against the same starting standards, i.e., dependent calibration (more than one starting standard):

$$
\begin{gathered}
u_{s}=\frac{U_{s 1}}{\mathrm{k}_{\text {factor1 }}}+\frac{U_{s 2}}{\mathrm{k}_{\mathrm{factor} 2}}, \\
\text { or } \\
u_{s}=\frac{U_{s 1}}{\mathrm{k}_{\text {factor1 }}}+\frac{U_{s 2}}{\mathrm{k}_{\text {factor2 }}}+\frac{U_{s 3}}{\mathrm{k}_{\text {factor } 3}} \text {, etc. }
\end{gathered}
$$

Multiple starting restraint schemes with standards NOT calibrated at the same time as the starting standards, i.e., independent calibration (more than one starting standard):

$$
\begin{aligned}
& u_{s}=\sqrt{\left(\frac{U_{s 1}}{\mathrm{k}_{\mathrm{factor} 1}}\right)^{2}+\left(\frac{U_{s 2}}{\mathrm{k}_{\mathrm{factor} 2}}\right)^{2}}, \\
& \text { or } \\
& u_{s}=\sqrt{\left(\frac{U_{s 1}}{\mathrm{k}_{\mathrm{factor} 1}}\right)^{2}+\left(\frac{U_{s 2}}{\mathrm{k}_{\mathrm{factor} 2}}\right)^{2}+\left(\frac{U_{s 3}}{\mathrm{k}_{\mathrm{factor} 3}}\right)^{2}}, \text { etc. }
\end{aligned}
$$

4.2. Calculating the within-process standard deviation, $s_{w}$, for a particular series: 
For each particular weighing design, the observed within process standard deviation, $s_{w}$, along with its degrees of freedom, d.f., is pooled using the technique described in NISTIR 6969 Section 8.4.

$s_{w}=\sqrt{\frac{\left(d f_{1}\right) s_{1}^{2}+\left(d f_{2}\right) s_{2}^{2}+\ldots+\left(d f_{k}\right) s_{k}^{2}}{d f_{1}+d f_{2}+\ldots+d f_{k}}}$

4.3. Calculating the between-time standard deviation, $s_{b}$, for each particular series:

Establish a standard deviation over time, $s_{t}$, for each check standard over time. If a plot of the check standard shows no apparent drift, the between-time standard deviation may be calculated. The following formulae are used to calculate the between-time standard deviation for the particular series. If $s_{b}{ }^{2}$ is less than zero, then $s_{b}$ is treated as zero.

4.3.1. For the $3-1$ design with a single restraint, and a check standard that is either another single weight or a summation, the between time standard deviation is calculated using the following formula. The check standard may be in any position.

$$
\begin{gathered}
s_{b}=\frac{1}{K_{2}} \sqrt{s_{t}^{2}-K_{1}^{2} s_{w}^{2}} \\
K_{1}=0.8165 \\
K_{2}=1.4142 \\
s_{b}=\frac{1}{1.4142} \sqrt{s_{t}^{2}-0.8165^{2} s_{w}^{2}}
\end{gathered}
$$

4.3.2. Using a 4-1 design with two restraints, and the check standard is the difference between the two restraints, the next equation may be used to calculate the between-time standard deviation. If another weight in the series is used as the check standard, another equation is needed.

$$
\begin{gathered}
s_{b}=\frac{1}{K_{2}} \sqrt{s_{t}^{2}-K_{1}^{2} s_{w}^{2}} \\
K_{1}=0.7071 \\
K_{2}=1.4141 \\
s_{b}=\frac{1}{1.4141} \sqrt{s_{t}^{2}-0.7071^{2} s_{w}^{2}}
\end{gathered}
$$

4.3.3. Using a 4-1 design with two restraints, and with a single check standard occupying any of the remaining positions, the next equation may be used to calculate the between-time standard deviation. 


$$
\begin{gathered}
s_{b}=\frac{1}{K_{2}} \sqrt{s_{t}^{2}-K_{1}^{2} s_{w}^{2}} \\
K_{1}=0.6124 \\
K_{2}=1.2247 \\
s_{b}=\frac{1}{1.2247} \sqrt{s_{t}^{2}-0.6124^{2} s_{w}^{2}}
\end{gathered}
$$

4.3.4. Using a 5-1 design with two restraints, and the check standard is the difference between the two restraints, the next equation may be used to calculate the between-time standard deviation. If another weight in the series is used as the check standard, another equation is needed.

$$
\begin{gathered}
s_{b}=\frac{1}{K_{2}} \sqrt{s_{t}^{2}-K_{1}^{2} s_{w}^{2}} \\
K_{1}=0.6325 \\
K_{2}=1.4142 \\
s_{b}=\frac{1}{1.4142} \sqrt{s_{t}^{2}-0.6325^{2} s_{w}^{2}}
\end{gathered}
$$

4.3.5. Using a 5-1 design with two restraints, and with a single check standard occupying any of the remaining positions, the next equation may be used to calculate the between-time standard deviation.

$$
\begin{gathered}
s_{b}=\frac{1}{K_{2}} \sqrt{s_{t}^{2}-K_{1}^{2} s_{w}^{2}} \\
K_{1}=0.5477 \\
K_{2}=1.2247 \\
s_{b}=\frac{1}{1.2247} \sqrt{s_{t}^{2}-0.5477^{2} s_{w}^{2}}
\end{gathered}
$$

4.3.6. In the second series (C.2), six weights are involved (500 g, 300 g, 200 g, $100 \mathrm{~g}$, Check $100 \mathrm{~g}$, and a summation $100 \mathrm{~g}$ ). Calculate the standard deviations of the mass values for the Check $100 \mathrm{~g}\left(s_{t}\right)$ and plot the results to evaluate the presence or lack of drift. If no drift is present, the following formula is used to calculate the between-time standard deviation for this series and all subsequent C.2 series. Subsequent series include the following check standards: $100 \mathrm{~g}, 10 \mathrm{~g}, 1 \mathrm{~g}, 100 \mathrm{mg}, 10 \mathrm{mg}$, and $1 \mathrm{mg}$. If $s_{b}{ }^{2}$ is less than zero, then $s_{b}$ is treated as zero. 


$$
\begin{gathered}
s_{b}=\frac{1}{K_{2}} \sqrt{s_{t}^{2}-K_{1}^{2} s_{w}^{2}} \\
K_{1}=0.3551 \\
K_{2}=1.0149 \\
s_{b}=\frac{1}{1.0149} \sqrt{s_{t}^{2}-0.3551^{2} s_{w}^{2}}
\end{gathered}
$$

4.3.7. If a C.1 series is used, the following equation is used to calculate the between-time standard deviation when the check standard is in either of the last two positions:

$$
\begin{gathered}
s_{b}=\frac{1}{K_{2}} \sqrt{s_{t}^{2}-K_{1}^{2} s_{w}^{2}} \\
K_{1}=0.4253 \\
K_{2}=1.0149 \\
s_{b}=\frac{1}{1.0149} \sqrt{s_{t}^{2}-0.4253^{2} s_{w}^{2}}
\end{gathered}
$$

4.3.8. The between-time formulae shown here are those that are most common and are for descending series only. If another restraint or check standard is used, or if an ascending series is used, another formula will be needed. These formulae are statistically derived, based on the least squares analysis of the weighing design, and assume a normal, non-drifting distribution of measurement results. Equations for some other weighing designs may be calculated using the NIST Electronic Engineering Statistics Handbook. Section 2.3.3.2 "Solutions to Calibration Designs" gives an overview for deriving the solutions to weighing designs. It also provides the unifying equation for $s_{b}$ (it is called $s_{\text {days }}$ in the electronic handbook). To clarify the difference in terminology and notation the unifying equation for $\mathrm{s}_{\mathrm{b}}$ is presented as:

$$
s_{\text {days }}=\frac{1}{K_{2}} \sqrt{s_{2}^{2}-K_{1}^{2} s_{1}^{2}} \quad \begin{aligned}
& s_{\text {days }} \equiv s_{b} \\
& s_{1} \equiv s_{w} \\
& s_{2} \equiv s_{t}
\end{aligned} \quad s_{b}=\frac{1}{K_{2}} \sqrt{s_{t}^{2}-K_{1}^{2} s_{w}^{2}}
$$

Section 2.3.4.1 “Mass Weights” provides the solutions for 17 weighing designs used for decreasing weight sets, 6 weighing designs for increasing weight sets and 1 design for pound weights. $K_{1}$ is located in the portion of the solution titled "Factors for Repeatability Standard Deviations", and $\mathrm{K}_{2}$ is located in the portion titled "Factors for Between-Day Standard Deviations”.

4.3.9. Note that there is a supplemental job aid spreadsheet that is available and includes several hundred weighing designs with associated $\mathrm{K}_{1}$ and $\mathrm{K}_{2}$ 
values and the equations for calculating between time standard deviations. The latest version of this spreadsheet is generally posted on the NIST website with this Standard Operating Procedure.

\section{Certificate}

See SOP 1, for Preparation of Calibration Certificates. Report measurement results as printed in Tables I and II as generated by the Mass Code. Actual text of the Mass Code certificate must be modified for each laboratory in order to be ISO/IEC 17025 compliant and to reflect accurate uncertainty values. See SOP 4 or 5 for examples of suitable uncertainty budget tables and components. 